\title{
Relación exhumación-deformación cenozoica de la Serranía del Interior Occidental, Venezuela, mediante modelado termocinemático 2D
}

\author{
Cenozoic exhumation-deformation relationship of the Serranía del Interior Occidental, Venezuela, \\ using 2D thermokinematic modeling
}

Ana Jazmín Rodríguez-Lara ${ }^{1, *}$, Mauricio A. Bermúdez ${ }^{1}$, Jaime Pérez de Armas $^{2}$

${ }^{1}$ Escuela de Ingeniería Geológica, Universidad Pedagógica y Tecnológica de Colombia, Calle 4 Sur No. 15-134, 15210, Sogamoso-Boyacá, Colombia.

2 Departamento de Ciencias de la Tierra, MS-126, Universidad Rice, 77005, Houston, Texas, USA.

* Autor para correspondencia: (A. J. Rodríguez-Lara)anajazmin.rodriguez@uptc.edu.co

\begin{abstract}
Cómo citar este artículo:
Rodríguez-Lara, A. J., Bermúdez, M. A.,Pérez de Armas, J., 2021, Relación exhumacióndeformación cenozoica de la Serranía del Interior Occidental, Venezuela, mediante modelado termocinemático 2D: Boletín de la Sociedad Geológica Mexicana, 73 (2), A100221. http://dx.doi.org/10.18268/ BSGM202lv73n2a100221
\end{abstract}

Manuscrito recibido: 30 de Agosto de 2020 Manuscrito corregido: 25 de Noviembre de 2020 Manuscrito aceptado: 20 de Diciembre de 2020

La revisión por pares es responsabilidad de la Universidad Nacional Autónoma de México.

Esteesun artículo de acceso abierto bajo la licencia CCBY-NCSA (https://creativecommons.org/licenses/by-nc-sa/4.0/)

\section{RESUMEN}

En el centro-norte de Venezuela se encuentra la Cordillera de la Costa, conformada por la Serranía del Interior y la Serranía del Litoral, separadas por el Sistema de Fallas La Victoria. Esta investigación combina restauración estructural y modelado termocinemático 2D, edades de trazas de fisión en apatitas, datos sismológicos y flujos de calor de la zona, para reconstruir la historia de deformación y asociar la actividad de las fallas a la sismicidad presente. Se elaboró un mapa de fallas cuaternarias asociadas con el comportamiento termal y la actividad sísmica. El modelado termocinemático 2D permitió predecir edades en superficie e historias tiempo-Temperatura, las cuales fueron comparadas con datos observados en la zona de estudio. Nuestros resultados sugieren que las rocas fueron enterradas hasta el Eoceno, cuando la placa del Caribe choca con la parte central norte de Suramérica. Discriminamos 4 pulsos tectónicos de enfriamiento: 48 a $40 \mathrm{Ma}$, 40 a $23 \mathrm{Ma}, 23$ a 5 y 5 a $0 \mathrm{Ma}$. El primero relacionado con la convergencia entre las placas del Caribe y Sudamericana, causando el emplazamiento de las Napas de Lara, el segundo relacionado con el enfriamiento causado por la subducción de la placa del Caribe por debajo del cinturón deformado del Caribe, el tercero corresponde a la continuación de la subducción de la placa del Caribe bajo la placa sudamericana, debido a la reactivación de fallas de tipo transpresivo y el último relaciona el avance de la Placa del Caribe hacia el este y la reactivación de importantes sistemas de fallas rumbo-deslizantes. A pesar de que existe una importante actividad sísmica en las montañas del Caribe, en este sector de la Serranía del Interior no se observa una distribución significativa de sismos; adicionalmente, la zona se caracteriza por presentar un flujo de calor medio.

Palabras clave: termocronología, sismicidad, modelado termocinemático, tectónica, compresión, flujo de calor.

\section{ABSTRACT}

In the center-north of Venezuela is the Cordillera de la Costa, formed by the Serrania del Interior and the Serrania del Litoral in Venezuela, separated by the La Victoria Fault System. This research combines $2 D$ structural restoration and thermokinematic modeling, apatite fission-track, seismological data and heat flow of the area, to reconstruct the deformation history and associate fault activity to the present-day seismicity. A map of Quaternary faults associated with thermal behavior and seismic activity was elaborated. The thermokinematic modeling allowing us predicting surface ages and time-temperature histories which were compared with data observed in the study zone. Our results suggest that the rocks were buried until the Eocene, when the Caribbean plate collides with the north central part of South America. We discriminated 4 tectonic cooling pulses: 48 to $40 \mathrm{Ma}, 40$ to $23 \mathrm{Ma}, 23$ to 5 and 5 to $0 \mathrm{Ma}$. The first one is related to the convergence between the Caribbean and South American plates, causing the emplacement of the Lara Nappes, the second one is related to the cooling of rocks caused during rocks transport to the surface product of the subduction of the Caribbean plate under the deformed Caribbean belt, the third one corresponds to the continuation of the subduction of the Caribbean plate under the South American plate, due to the reactivation of transpressive type faults and the last one relates to the advance of the Caribbean plate towards the east and the reactivation of important strike-slip faults. Despite the fact that there is an important seismic activity in the Caribbean mountains, in this sector of the Serrania del Interior there is not a significant distribution of earthquakes.

Keywords: thermochronology, seismicity, thermokinematic modeling, tectonics, compression, heat flow. 


\section{Introducción}

Una compleja interacción entre las placas Caribe y Suramericana (Figura 1A; Audemard, 2009, 2014; Pindell y Kennan, 2009; Weber et al., 2015; Pérez et al., 2018, entre otras) ha generado en la parte central norte de Suramérica el sistema montañoso denominado Cordillera de la Costa o Montañas del Caribe ("Caribbean Mountains"), que a su vez está conformado por la Serranía del Interior y la Serranía del Litoral en Venezuela (Figura 1B y $1 \mathrm{C})$, estando ambas serranías separadas por el Sistema de Fallas La Victoria (e.g., Schubert, 1983; Audemard et al., 1995; Figura 1B), y encontrándose la subcuenca Guárico al sur de la parte central de la Serranía del Interior (Figura 1B). Los procesos que se han desarrollado a partir del movimiento entre estas dos placas incluyen diferentes ciclos orogénicos mesozoico-cenozoicos y registran la obducción de terrenos alóctonos en la placa continental (e.g., Stephan, 1982; Pérez de Armas, 2005; Figura 2). La zona límite de la placa del Caribe y Suramérica constituye una zona compleja (e.g, Audemard y Audemard, 2002). La Placa del Caribe está delimitada por la placa Atlántica, de afinidad oceánica en el este, en el norte y sur por placas de afinidad continental como la placa Norteamericana y Suramericana, respectivamente, y por la placa de Cocos en el oeste (Audemard, 2009) (Figura 1A). La placa del Caribe se desplaza hoy en día hacia el este en relación con Suramérica, estando soportado por mediciones GPS (Freymueller et al. 1993; Pérez et al. 2001a, 2001b; 2018; Weber et al., 2001). Sin embargo, el norte de Suramérica refleja la interacción de las placas del Caribe, Suramérica, Nazca y la microplaca de Panamá. La deformación a lo largo del límite está impulsada por la convergencia oblicua (Silver et al., 1975; Pérez y Aggarwal, 1981; Stephan, 1982; Speed, 1985; Lugo y Mann, 1992; Russo y Speed, 1992; Audemard, 1993). En la actualidad, esta actividad es más intensa en el oeste que en el este.

El norte de Venezuela yace en la zona de interacción entre las placas Caribe y Suramérica, mientras que el oeste de Venezuela y el norte de
Colombia comprenden un número de bloques tectónicos o microplacas que interactúan entre sí (Audemard y Audemard, 2002; Cediel et al., 2003; Audemard, 2009). La zona de interacción entre las placas Caribe y Suramérica se extienden por más de 3000 km desde Colombia hasta Trinidad (Figura 1A) y constituye una amplia zona transpresiva activa que ha evolucionado desde el Cretácico al Reciente (Audemard, 1993, 2009; Singer y Audemard, 1997; Pindell et al., 1998; Ysaccis et al., 2000; Audemard et al., 2000, 2005; Giunta y Orioli, 2011). El límite norte de Suramérica está caracterizado por fallas rumbo-deslizantes, cabalgamientos y zonas de subducción, que acompañado de un fallamiento activo conducen a una actividad sísmica importante, un elevado flujo de calor y contrastantes espesores corticales (Figuras 1D-1G; Audemard, 1993, 1998, 2009, 2014; Taboada et al., 2000; Audemard et al. 2005, 2006, entre otras).

La convergencia entre las placas Caribe y Suramérica pudo haber sido NO-SE la mayor parte del tiempo y, por lo tanto, con respecto al margen continental suramericano, la tendencia fue predominantemente lateral-derecha oblicua con tendencia E-O. Así, la colisión de la placa del Caribe y el arco de islas de las Antillas Menores es altamente diacrónica, lo cual significa que ocurre en tres períodos de tiempo distintos: 1) en el oeste de Venezuela en el Paleoceno y el Eoceno, 2) en el centro-norte de Venezuela durante el Oligoceno, y 3) al este de Venezuela en el Mioceno (Lugo y Mann, 1995). Sabiendo que la convergencia entre las Placas Norteamericana y Suramericana comenzó durante el Paleoceno (Pindell, 1993), una interesante pregunta de investigación sería si en el centro-norte de Venezuela, esta convergencia causó la deformación del Eoceno en la zona antes de la formación de estructuras por deformación compresional (Pérez de Armas, 2005). Pindell (1993) sugiere que una fase de contracción entre las placas Norteamérica y Suramérica podría haber deformado la corteza del Proto-Caribe, formando una zona de subducción incipiente y el subsiguiente levantamiento temprano de algunos 
A

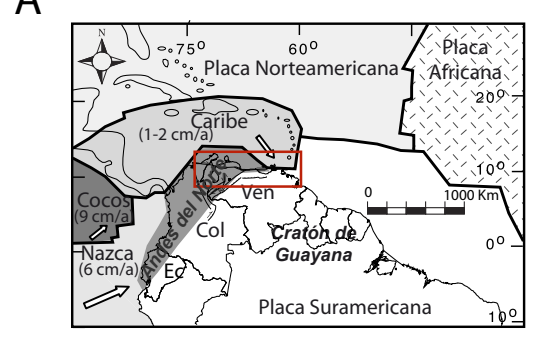

C

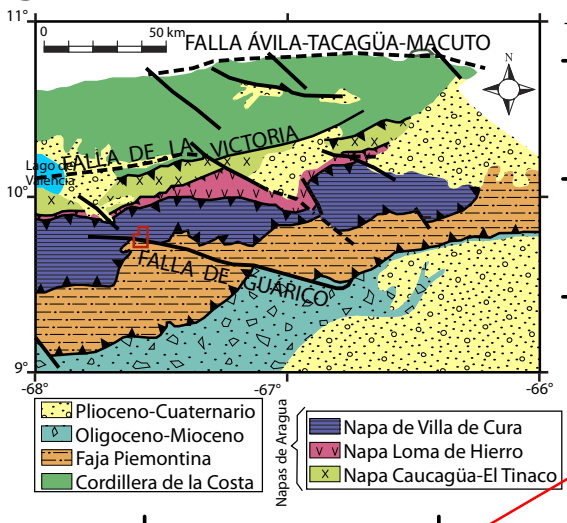

$\mathrm{E}$

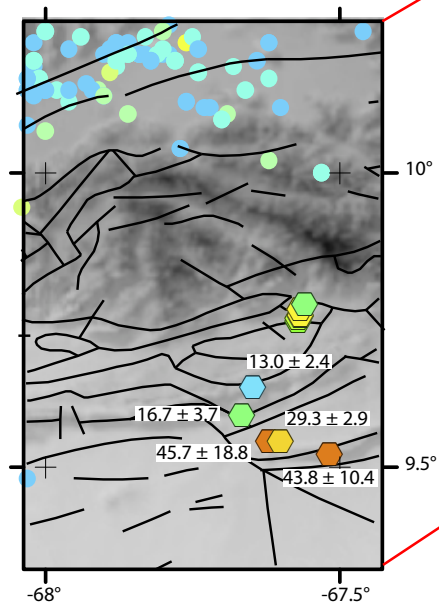

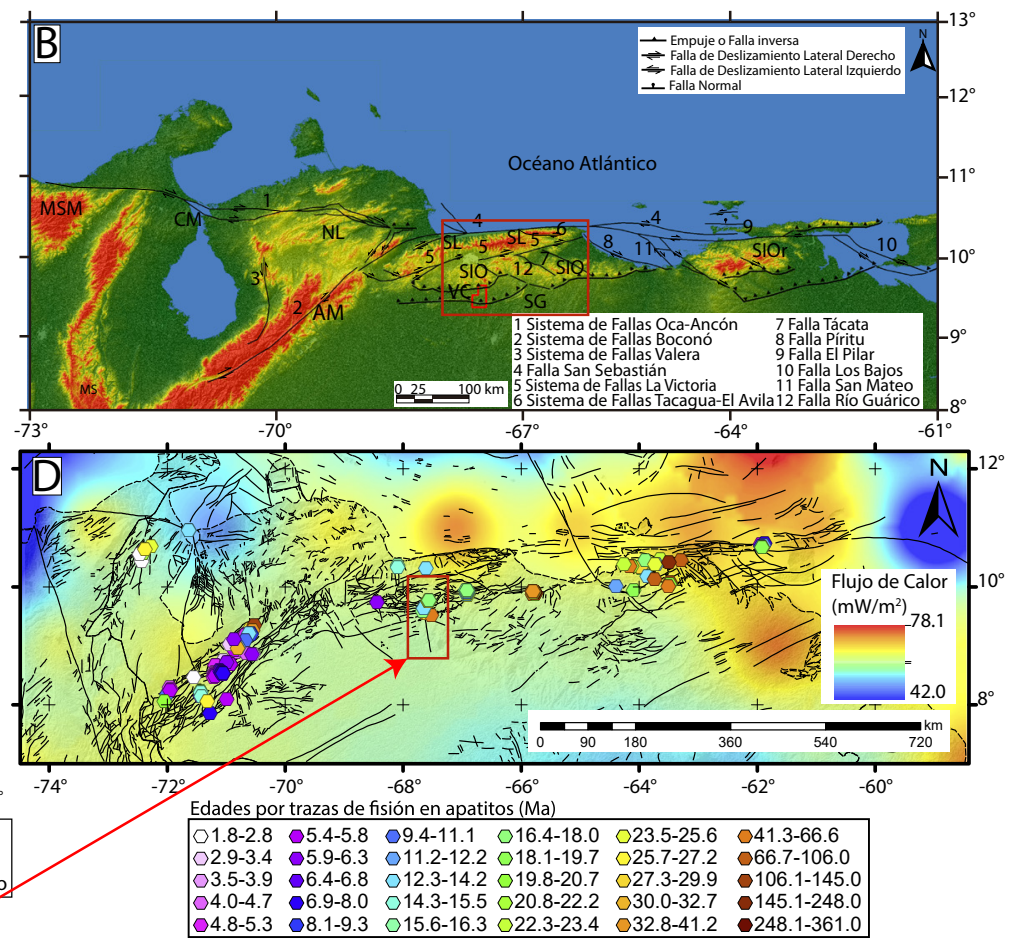

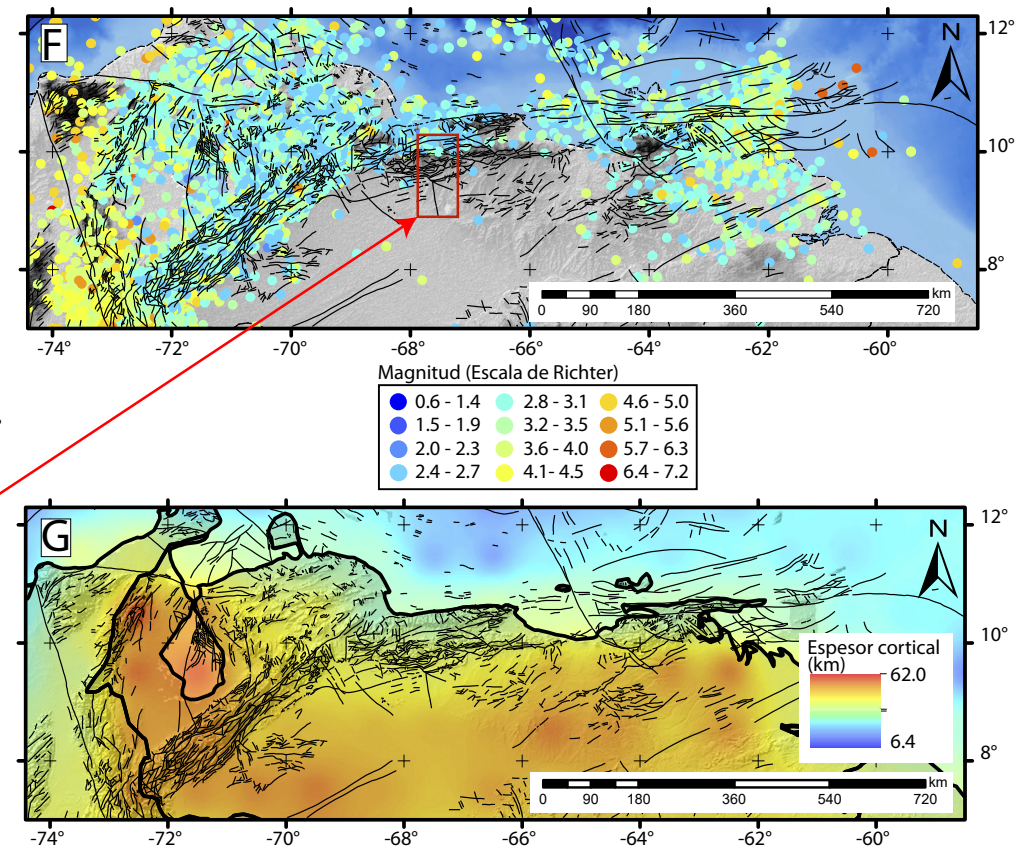

Figura 1 (A) Contexto geodinámico actual (Modificado de Cediel et al., 2003). (B) Modelo de elevación digital obtenidos del sensor ALOS-PALSAR a una resolución de 30 metros (https://www.eorc.jaxa.jp/ALOS/en/aw3d30/index.htm) mostrando la ubicación de fallas y principales estructuras de la parte central norte de Suramérica, en esta figura MSM: Macizo de Santa Marta, MS: Macizo de Santander, CM: Cuenca de Maracaibo, AM: Andes de Mérida, NL: Napas de Lara, SL: Serranía Litoral, SIO: Serranía del Interior Occidental, SIOr: Serranía del Interior Oriental, VC: Napas de Villa de Cura y SG: Subcuenca Guárico (Las fallas cuaternarias -con actividad sísmica- fueron tomadas de Audemard et al., 2000). (C) Principales bloques tectónicos, unidades, napas y fajas (Modificado de Beck, 1985). (D) Mapa de flujo de calor (Davies, 2013), detalle de fallas y lineamientos de la región Caribe (French y Schenk, USGS, Denver, CO, https://certmapper. cr.usgs.gov/data/we/ofr97470k/spatial/shape/flt6bg.zip) y compilación de edades termocronológicas por trazas de fisión en la parte central norte de Suramérica (Tomado de Bermúdez y Flores, 2019). (E) Acercamiento de la zona de estudio mostrando las cinco edades termocronológicas de Pérez de Armas (2005) consideradas en esta investigación. (F) Mapa de sombras derivada del modelo de elevación digital ALOS-PALSAR (Figura B) y eventos sísmicos entre 1911 a 2020 (compilado a partir de la base de datos de FUNVISIS) (G) Mapa de espesor cortical derivada del modelo CRUST 1.0 (Bassin et al. 2000; Laske et al., 2013), sobre este último mapa se han colocado como referencia las fallas de la figura F. 
sectores de la Cordillera de la Costa y el norte de Trinidad. Esas fases deformacionales ya habían sido discriminadas gracias a trabajos de campo realizados previamente por Peirson $(1963,1965)$, Menéndez (1966), Bell (1968), Beck (1978, 1985b, 1985c), Aguasuelos Ingeniería (1990), Stephan et al. (1990) quienes cartografiaron la parte central y occidental de la Serranía del Interior.

Adicionalmente, desde un punto de vista absolutista, Bellon et al. (1985, en Beck, 1985a), Santamaría y Schubert (1975), Loubet et al. (1980, 1985), Girard (1981), Sagna et al. (1988), Sagna (1990) y Lar (1992), proporcionan edades geocronológicas K-Ar y la relacionan con la geoquímica de rocas máficas, lo cual permite establecer ambientes de formación de las rocas. Además, empleando los métodos de termocronología por trazas de fisión en apatito y circones, y Ar-Ar (Kohn et al., 1984a; Sisson et al., 2005; Pérez de Armas, 2005; Locke y Garver; 2005, Cruz et al., 2007; Flores et al., 2017) se ha tratado de dilucidar las edades de deformación de esta parte central norte de Suramérica. Sin embargo, dos factores dificultan la interpretación de tales edades: 1) la escasa distribución espacial de las mismas, tomando en cuenta las principales estructuras de la zona, y 2) el complejo contexto geodinámico activo. Por estas razones, en la presente investigación nos planteamos como objetivo analizar ¿cómo las tres principales fases de deformación mencionadas anteriormente, reproducirían el patrón de edades termocronológicas e históricas tiempo-temperatura observadas en el área?, y evaluar el posible papel de estructuras menores en la distribución observada de edades termocronológicas, así como analizar el rol de la erosión, flujo de calor y geometría de fallas sobre la distribución de edades termocronológicas encontradas en un sector de la Serranía del Interior. Este objetivo sólo es posible realizarlo a través de la combinación de paquetes informáticos como: FetKin (Almendral et al., 2015a; Mora et al., 2015) y software de reconstitución cinemática como $\mathrm{MOVE}^{\circledR}$, donde es posible incluir mecanismos geológicos, como por ejemplo el acortamiento de la cadena producido por la interacción de las placas antes mencionadas. A pesar de que se consideraron distintas secciones balanceadas, incluida la original de Pérez de Armas (2005), se tomaron en cuenta posibles modificaciones a su reconstrucción balanceada estructural, y se compararon las edades observadas por distintos autores con las predichas por el modelado termocinemático 2D. Esta comparación permite validar el modelo termocinemático, e incluso probar distintos valores de acortamiento de la cadena, flujo de calor y reactivación de distintas fallas presentes en la zona de estudio. Todo lo anterior resulta novedoso para esta área, ya que hasta el momento para la interpretación de los datos de termocronología no se habían tomado en cuenta estas variables.

\section{Breve cronología del conocimiento geológico del Norte de Suramérica}

El estudio de la geología del norte de Venezuela (Cordillera de la Costa y Serranía del Interior) comienza desde la época de la colonización en el siglo XVI con el inventario de los recursos mineros, y ha continuado hasta la actualidad (Urbani, 2012, 2018). Los primeros levantamientos geológicos fueron realizados por Agustín Codazzi (1841a, 1841b), Hermann Karsten (1850, 1858, 1862, 1886), George Wall (1860a, 1860b) quien es el primero en mencionar la presencia de eclogitas de gran relevancia para la tectónica de placas. Estos estudios fueron seguidos por Albert Schottky (1877) y Wilhelm F. Sievers (1888).

En la primera mitad del siglo XX, destacan los trabajos realizados por la campaña de exploración geológica de la empresa Shell entre 1911 y 1916 (Urbani, 2012), el mapa geológico generado por Ralph Alexander Liddle (1928, 1946), quien muestra como una unidad aparte a la Serranía del Interior, y el de Walter Hermann Bucher (1950), el cual de acuerdo con Urbani (2012), presenta la más fiel distribución de las rocas volcánicas de Villa de Cura.

A partir de 1947, el Profesor Harry Hess de la Universidad de Princeton organiza el "Proyecto 
de Investigaciones Geológicas del Caribe", otorgando una especial importancia al norte de Venezuela, ya que en los años 30 detecta una anomalía gravimétrica extensa y negativa a lo largo del Caribe, dicha anomalía comprende Las Antillas Mayores, las Antillas Menores y el norte de Suramérica (Hess, 1938 en Urbani, 2012). Los trabajos básicos de cartografía geológica fueron realizados por tesistas doctorales de Hess, entre los cuales destacan: Gabriel Dengo (1947, 1950a, 1950b, 1951, 1953) en la región de Caracas, Raymond Smith (1953) para la zona de Los TequesTiara, James MacLachlan (1952) en La Victoria, Reginald Shagam (1960) en la zona de Aragua Central, Theodore Konigsmark (1958), Harry Jarvis (1966) en la zona de Río Pao a Río Tiznados, Michael Piburn (1968) en Villa de Cura, y John Bell (1968) en el transecto Camatagua-Valle Morín, cuya investigación permitió discriminar las etapas evolutivas en el desarrollo de los arcos de islas y sistemas montañosos alpinos.

Entre 1966 y 1976, el Ministerio de Minas e Hidrocarburos $(\mathrm{MMH})$ de Venezuela inicia un proyecto de cartografía geológica que resulta en el mapa geológico estructural de Venezuela a escala 1:500.000 (Bellizzia et al., 1976). Gracias a un convenio entre universidades francesas y el MMH culminan sus tesis doctorales Jean Françoise Stephan (1982) y Christian Beck (1985a). Stephan, quien se enfoca en la región de Barquisimeto, introduce el importante concepto de las Napas de Lara, el cual permite entender el desarrollo de la parte occidental de la Cordillera de la Costa (Figuras 1B y C) y su interacción con Los Andes de Mérida.

Beck (1985a) se enfoca en la región de Altagracia de Orituco hasta Ocumare del Tuy, destacando entre sus aportes la distinción de las napas de la Serranía del Interior: 1) Caucagua-El Tinaco, 2) Loma de Hierro y 3) Villa de Cura (Figura 1C), y definir los tipos de contacto entre la las unidades de la Napa Caucagua-El Tinaco, de aquella al norte hoy denominada Faja Caracas (Figura 1C; Urbani, 2012, 2018). Beck (1985a) es el primero en utilizar las edades isotópicas disponibles hasta el momento para establecer equivalencias laterales entre unidades de la Faja Caracas, y presenta la sección geológica generalizada hasta el momento más aceptada de la Cordillera de la Costa.

Blin (1989) se enfoca en la franja o faja piemontina (Figura 1C) al sur de El Tinaco y El Pao, estado Cojedes, realizando un estudio detallado de las unidades sedimentarias. Hacia la zona norte, realizó minuciosos transeptos que permitieron entender las relaciones de campo entre las diversas unidades geológicas.

Desde 1942 al presente, la Escuela de Ingeniería Geológica de la Universidad Central de Venezuela, la Fundación Venezolana de Investigaciones Sismológicas (FUNVISIS) y Petróleos de Venezuela (PDVSA) han realizado numerosos trabajos de cartografía geológica, estudios sísmicos, y de neotectónica a lo largo de la Cordillera de la Costa y la Serranía del Interior occidental, central y oriental. La presente investigación, ubicada en esta región, se centra específicamente en un sector de la Serranía del Interior Occidental (Pérez de Armas, 2005), en la zona limitada por las coordenadas $67.7145 \mathrm{O}, 67.4465 \mathrm{O}$ y $9.5213 \mathrm{~N}, 9.8887 \mathrm{~N}$.

\section{Contexto geodinámico de la Serranía del Interior Occidental}

La geodinámica regional del área de estudio debe entenderse desde el contexto de la tectónica de placas Suramericana y del Caribe. La placa del Caribe es el resultado de la interacción de otras placas mayores como Nazca, Cocos, Norteamericana y Suramericana, desde el Mesozoico hasta el presente (Boschman et al., 2014). La placa del Caribe tiene un movimiento relativo respecto a las otras, con una dirección predominante hacia el E, aunada a una componente menor en dirección N-S (Pennington, 1981).

A continuación, se describen algunos de los procesos más importantes en la formación y desplazamiento de la Placa del Caribe, tomando en cuenta la teoría donde se postula que esta placa fue generada en el Pacifico norte y migró hacia el este, entre Norte América y Suramérica en el Cretácico Tardío (Pindell y Kennan, 2009; Boschman et al., 2014). 
Suramérica y África constituyeron una sola placa hasta el Aptiense, y la subsecuente apertura del Atlántico Ecuatorial aparentemente tuvo poco efecto en la dirección del movimiento relativo entre la Placa Norteamericana y Sudamericana (Figura 2A) (Pindell y Kennan, 2001b), dando paso a la litosfera Protocaribeña. El desarrollo de sistemas de arcos intra-oceánicos, extendiéndose desde Costa Rica hasta Ecuador, indica que la Placa del Caribe se separó de la Placa de Farallón en el Aptiense y desde entonces se mueve más despacio en sentido NE o E relativo a Norteamérica (e.g., Hernández, 2006). Durante el Albiense y el Cretácico superior el movimiento de placas y la estratigrafía sugieren el establecimiento de un margen pasivo en la mayor parte del norte de Suramérica (Pindell y Kennan, 2009). Éste se caracterizó por la falta de deformación tectónica generalizada (Mann et al., 2006).

La convergencia entre Norte y Suramérica comenzó durante el Paleoceno y en el Eoceno medio (Figura 2B) el acortamiento pudo haber sido de aproximadamente $70 \mathrm{~km}$ (Pindell, 1993), lo cual se vio reflejado en el engrosamiento estructural, levantamiento y erosión del margen pasivo del norte de Suramérica (Pindell y Kennan, 2001a). Pindell y Kennan (2009) sugieren que la contracción entre las placas Norteamericana y Suramericana pudo haber deformado la corteza protocaribeña, formando una incipiente zona de subducción (Figura 2B).

El acercamiento del Caribe, desde el Oeste, comienza a afectar los terrenos de Venezuela oriental desde el Eoceno Tardío hasta el Oligoceno Temprano (Figura 2B y 2C) (Hernández, 2006). En el Mioceno temprano continúa la transpresión oblicua entre la Placa del Caribe y la Sudamericana (Figura 2B y 2C) (Pindell y Kennan, 2001a).

A finales del Mioceno medio hasta el Mioceno tardío se desarrolló un cambio de estilo en el movimiento de la placa del Caribe respecto a Suramérica, pasando de un sistema compresivo a uno de tipo transpresivo (Audemard 1993, 1998, 2009). Según Sykes et al., (1982), este régimen geodinámico debió mantenerse muy similar durante al menos los últimos $11 \mathrm{Ma}$, iniciando en el periodo correspondiente al Tortoniense, confiriéndole al Caribe su forma actual.

Finalmente, se encuentra la etapa que comprende la colisión oblicua del arco del Caribe con el continente Suramericano (Audemard 1993; 1998; 2009; Van der Hilst y Mann, 1994; Pindell et al., 2005; Escalona y Mann, 2011 ), y es caracterizada por: 1) rotura completa de la losa suramericana que se inclina hacia el norte; 2) extensión esteoeste del arco del Caribe a medida que se alarga paralelamente a su rumbo formando fallas normales oblicuas que producen profundas fracturas y medios grábenes y 3) una extensa deformación caracterizada por fallas y plegamientos.

\section{Contexto geológico de la Serranía del Interior Occidental}

La zona de estudio antes mencionada está constituida por rocas con edades que van desde el Jurásico hasta el Mioceno (Figura 2A) las cuales han sufrido importantes eventos de deformación y exhumación. A continuación, se presenta una breve descripción de las formaciones, según el Léxico Estratigráfico de Venezuela (Ministerio de Minas e Hidrocarburos, 1970). El Grupo Villa de Cura, de edad jurásica superior-cretácica (Neocomiano), está constituido por una asociación compleja de rocas mayoritariamente metavolcánicas expuestas en las cercanías de Villa de Cura, estado Aragua. De acuerdo con Shagam (1960) y Piburn (1968, en Beck (1985a), este grupo representa un conjunto de espesor considerable (4 a $5 \mathrm{~km}$ ) y relativamente monótono, donde la parte basal se distingue de la parte superior por la ausencia de lavas y una deformación más intensa, mientras que la parte superior presenta lavas muy porfiríticas. La edad del Grupo Villa de Cura fue establecida por distintos autores (Shagam, 1960; Seiders, 1965; Menéndez, 1966, Oxburgh, 1965; Piburn, 1968; Bellizzia, 1972 y Maresch, 1974, entre otros) de forma indirecta y deducida por reconstituciones paleogeográficas y geodinámicas 
que consideran toda la cadena de las Montañas Caribe (Beck, 1985a). La Formación Garrapata de edad cretácica (Coniaciense - Santoniense), está compuesta por un conjunto de unidades cíclicas, de origen turbidítico, cada una de las cuales consta de un conglomerado basal, seguido arriba por grauvacas líticas, limolitas y lutitas con ocasionales capas de caliza. La Formación Mucaria de edad cretácica (Campaniense-Maastrichtiense), está conformada por un conjunto de lutitas silíceas de color gris oscuro, con algunas calizas y microconglomerados, que afloran en el norte de los estados Cojedes y Portuguesa. La Formación Guárico del Cretácico (Maastrichtiense)-Terciario (Paleoceno-Eoceno), está caracterizada por una predominancia de depósitos de flysch compuestos de espesas secuencias de alternancias monótonas de areniscas y lutitas delgadas, con abundantes icnofósiles. La Formación Quebradón del Terciario (Oligoceno tardío a Mioceno medio), está

\section{A Época Mecanismo Estructura Formación}

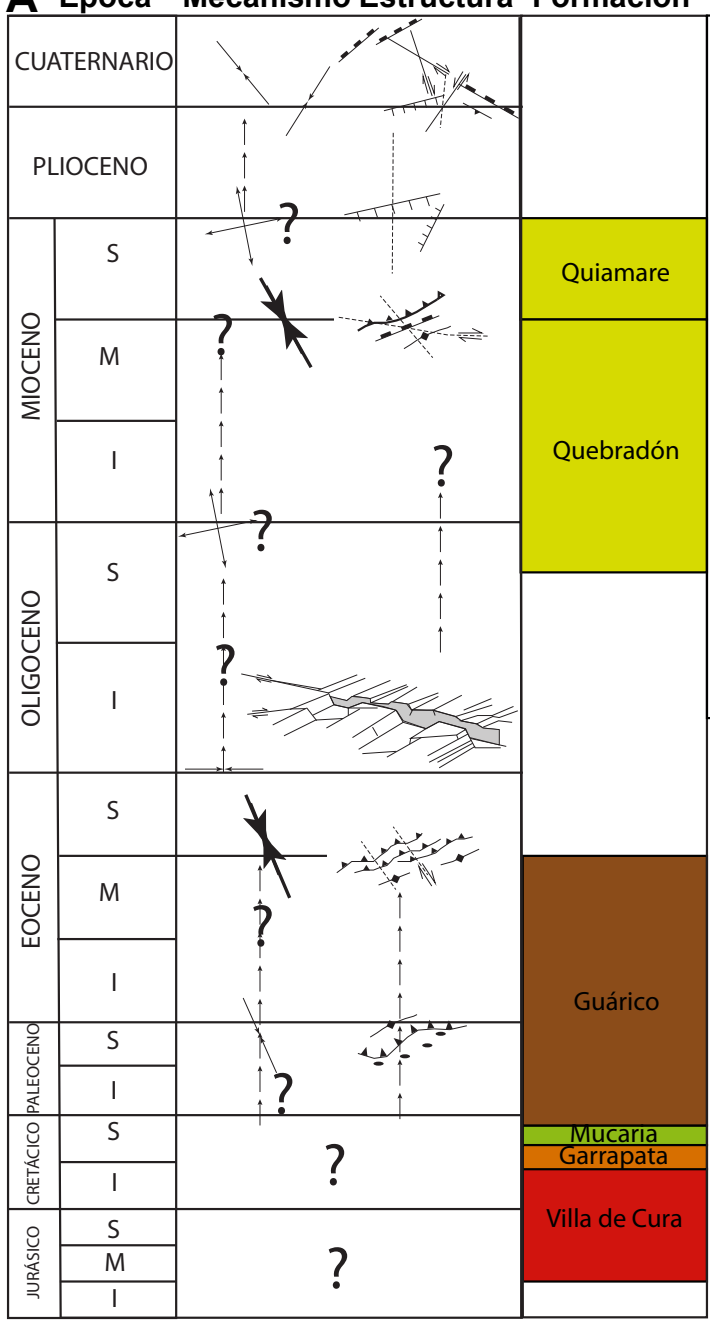

B

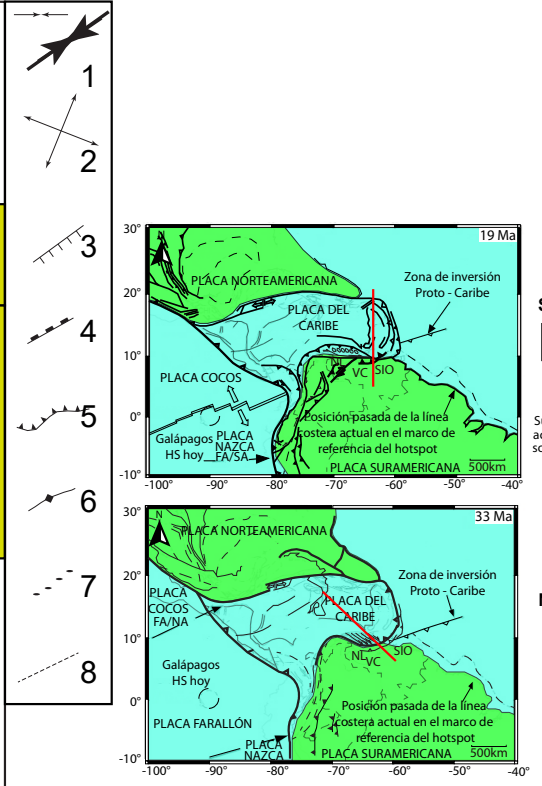

\section{C}

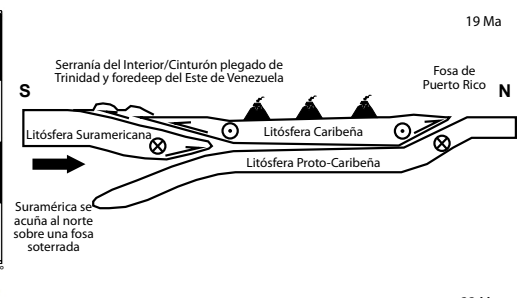

$33 \mathrm{Ma}$
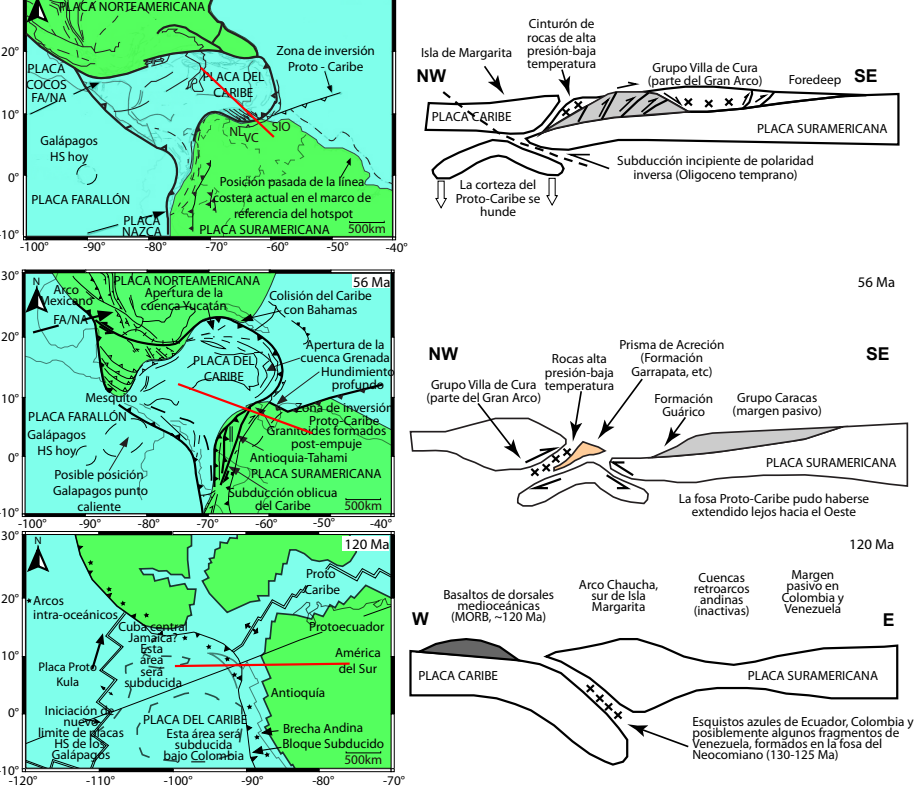

Figura 2 A) Cronología, geometría de las deformaciones cenozoicas y unidades sedimentarias depositadas en la región de estudio En esta figura, los números corresponden a: 1 compresión; 2 extensión multidireccional, 3 falla normal, 4 falla inversa, 5 cabalgamientos, 6 pliegues, 7 formación de olistolistos y 8 activación de movimiento rumbo-lateral hipotético (Modificado de Beck, $1985 a$ ). B) Reconstrucción palinspática de la formación y desplazamiento de la placa del Caribe (Modificado de Pindell et al., 2005 y Pindell y Kennan, 2009), las líneas rojas corresponden a la ubicación aproximada de los perfiles sin escala de la figura 2C. C) Secciones transversales esquemáticas ilustrando los posibles mecanismos de formación y emplazamiento de terrenos alóctonos y rocas de alta presión baja temperatura (Modificado de Pindell et al., 2005). 
compuesta por lutitas mal estratificadas y poco resistentes a la erosión, de color variable entre azul-gris y negro, en parte carbonáceas, con lignitos delgados intercalados localmente. Por último, la Formación Quiamare de edad Terciaria (Mioceno temprano a tardío), está constituida por una secuencia monótona de arcilitas gris verdosas, rojas pardas y gris-azulado, en capas plurimétricas poco definidas, con intercalación de areniscas guijarrosas, lutitas carbonáceas y lignito en capas lenticulares, métricas.

\subsection{GENERALIDADES: PROGESOS, ESTILOS, Y EDADES DE DEFORMACIÓN}

El área de estudio comprende dos zonas bien definidas (Figura 1G): 1) las llamadas "Fajas Piemontinas" de Bell (1968), y 2) Las Napas de Aragua (Beck, 1985a). El Cinturón o Faja Piemontina (Bell 1968; Beck, 1985a) está conformado por una secuencia tipo flysch y por la Formación Guárico. Ambos conforman una espesa secuencia sedimentaria terrígena y turbidítica de edad paleocena-eocena inferior (Peirson et al., 1966; Bell, 1968; Beck, 1977; 1985a) depositada en una cuenca elongada con orientación OSO-ENE. De acuerdo con Beck (1985a), el depósito de este flysch se produce antes del período tectónico compresivo responsable de su plegamiento y levantamiento. Desde un punto de vista estructural, la zona Piemontina se caracteriza por la presencia de contactos anormales tangenciales (Bell, 1968; Gónzalez-Silva y Picard, 1972 en Beck, 1985a). De acuerdo con Beck (1977, 1985a), la tectonización de este sector corresponde a un deslizamiento gravitacional continuo desde finales del Cretácico (Senoniano superior) y hasta el Mioceno, donde en algunos sectores, se han discriminado episodios importantes de deformación por fallamiento normal y rumbo-lateral ocurridos durante el fin del Eoceno, Mioceno y Plio-Guaternario (Beck, 1978, Stephan et al., 1980; Audemard, 1984, 1997).

La tectonización de la Faja Piemontina está ligada al avance de las Napas de Aragua, donde una serie de estructuras tangenciales cuya vergencia es aproximadamente paralela al eje de la cadena (OSO-ENE; Beck, 1985a), se extienden desde el borde norte de la sección y se van inclinando hacia el sur. De sur a norte destacan: 1) una secuencia pliocena-cuaternaria, 2) la secuencia molásica oligo-miocena, en donde una banda de unos 20 a $25 \mathrm{~km}$ de ancho, se caracteriza por la presencia de pliegues que se cortan hacia el sur, y luego, más al norte, por superposiciones poco inclinadas que se cortan en pequeños flancos inversos. Tomando en cuenta el espesor de la secuencia molásica, los contactos parecen ser relativamente superficiales. A medida que se aproxima el frente de la Zona Piemontina, los contactos son más estrechos y verticales, y aparece una serie de fragmentos con saltos normales y reversos en forma alternante. 3) Las escamas frontales, una zona entre las secuencias molásicas descritas anteriormente y la Zona Piemontina, representan probablemente la base de la secuencia molásica (Beck, 1985a). Esta zona corresponde a un klippe complejo en la cual existen diferentes familias de cabalgamientos, constituyendo unidades deformacionales de distintas edades. Este conjunto de cabalgamientos es el resultado de las distintas fases de acortamiento de la cadena. 4) La Faja Piemontina ya descrita anteriormente y 5) las Napas de Aragua (Beck, 1985a) están conformadas de norte a sur por la Napa de Caucagua-El Tinaco, la Napa de Loma de Hierro, y la Napa de Villa de Cura (Figura 1G). Este conjunto de napas se forma en una segunda fase intra-senoniana, la cual está acompañada de deformación penetrativa y epimetamorfismo, desarrollándose estos últimos en la zona de la Cordillera de la Costa y en las Napas Caucagua-El Tinaco.

Del conjunto de napas que integran las Napas de Aragua, las Napas de Villa de Cura son las más importantes para el área de estudio considerada en vista del relieve que ellas conforman. Están constituidas por una serie de lavas y tobas volcánicas, que en algunos sectores son intercaladas con sedimentos siliciclásticas (Shagam, 1960; Oxburgh, 1965; Konigsmark, 1965; Piburn, 1968; Beck, 1985a). Las Napas de Villa de Cura fueron afectadas por una fase metamórfica de esquistos verdes a azules (Maresch, 1974), lo cual representa una parte del arco volcánico jurásico-cretácico inferior de la región Caribe. 
Según Beck (1985a), la interpretación estructural de la Napa de Villa de Cura conlleva diferentes problemas, pero uno de ellos, el más importante de acuerdo con ese autor, es la determinación de la polaridad a la escala de afloramiento. Este autor indica que no resulta una tarea sencilla determinar la polaridad, debido a la gran cantidad de deformación presente (pliegues isoclinales muy cerrados a escalas de centímetros a milímetros, presencia de boudines) y la dificultad de discriminar el carácter piroclástico o volcano-detrítico de los niveles de brechas y tobas. Los distintos y frecuentes contrastes litológicos que caracterizan al grupo Villa de Cura sugieren una respuesta muy variada a los diferentes estilos de deformación. Beck (1985a) describe algunos niveles donde la esquistosidad no se desarrolla hasta los niveles de metatobas ricas en cuarzo, otros en donde hay penetración ligera de la esquistosidad, y algunos sectores en donde éstas no se presentan. Empleando mediciones en campo, Beck (1985a) muestra los cambios en la esquistosidad desde forma de clivaje "strain-slip" a escala de centímetros (Pliegue P1), hasta zonas con ausencia de esquistosidad a nivel de la charnela (Pliegue P2) de un nivel más cuarzoso. Estas deformaciones están asociadas a un metamorfismo somero de edad $100 \pm 10$ Ma (Piburn, 1968 en Beck, 1985a), donde la coexistencia de esquistos azules y de grupos de esquistos verdes sugiere una movilidad diferencial del agua en este grupo; algunos niveles de esquistosidad se generan por rotación durante el metamorfismo.

Una serie de deformaciones separadas desde un punto de vista cronológico fueron determinadas por Beck (1985a) a partir de análisis estadísticos de las estratificaciones, identificando al menos cuatro tipos de deformaciones (Figura 2A). La primera, asociada con pliegues tipo kink, y clivajes de pliegues fracturados localmente relacionados con la esquistosidad. La segunda fase de deformación es asociada a un metamorfismo somero de alta presión y baja temperatura, que posiblemente ocurre en el Aptiense-Albiense. Las dos últimas deformaciones que afectan también el borde norte de la Zona Piemontina serían de edad eocena. La Figura 2A resume la cronología y geometría de las deformaciones cenozoicas ocurridas en la región de estudio, además de las formaciones depositadas en las distintas épocas, estando esta figura descrita en la siguiente sección.

\subsection{EXHUMAGIÓN Y DEFORMAGIÓN ASOGIADAS CON EL MARGO GEODINÁMICO}

Pangea inició su separación a mitad del período Jurásico (entre 201-145 Ma), con el desarrollo de una dorsal que abarcaba desde su océano interior (Tetis) hasta lo que sería el moderno Pacífico este. Esto ocasionó la separación de la actual Norteamérica de África, generando abundantes sistemas de fallas normales y el Atlántico norte, que comenzó a extenderse hacia el sur, lo que le tomó varios millones de años (Pindell, 1993).

Posteriormente, durante el período Cretácico (hace 140-150 Ma), el supercontinente Gondwana se dividió en cuatro continentes nuevos: África, Suramérica, India y la Antártida/Australia. Una vez ocurrida la ruptura de Pangea en el Jurásico, se genera el Proto-Caribe, una nueva corteza oceánica, mientras tanto el borde norte de Suramérica se desarrolla como un margen pasivo (Pindell et al., 2005). Desde 163 a 140 Ma hacia el Pacífico, se origina el Gran Arco del Caribe, y las placas Suramericana y Atlántico continúan avanzando hacia el oeste. Entre 140 a 120 Ma se genera una meseta oceánica o "plateau" llamada la Gran Provincia Ígnea del Caribe (Figura 3C). Entre 125 y $113 \mathrm{Ma}$ (Aptiense) la subducción del Gran Arco del Caribe continúa por debajo de Suramérica (Figura 2C) en esa fase se generan posiblemente las rocas del Terreno Villa de Cura que fueron formadas probablemente en un ambiente antearco y sometidas a subducción (Urbani, 2012, 2018). Desde $113 \mathrm{Ma}$ (Albiense tardío) hasta 72.1 Ma (Campaniense), el Grupo Villa de Cura fue sometido a subducción, lo cual les permite heredar asociaciones mineralógicas metamórficas de rocas de alta presión y baja temperatura. Desde 72.1 a 66 Ma se detiene la separación de las placas norteamericana y suramericana, y continúa el avance noreste del Gran Arco del Caribe, mientras tanto prosigue la sedimentación de unidades en el margen pasivo, 
entre esas unidades destacan las rocas madres por excelencia como las formaciones La Luna y Querecual, y otras unidades ricas en materia orgánica como Mucaria.

Entre 66 a 56 Ma (Paleoceno) las Bahamas impide el avance de la placa del Caribe hacia Norteamérica, esto ocasiona que la placa del Caribe migre hacia el este, haciendo que rocas (Grupo Villa de Cura) que conforman parte del Gran
Arco del Caribe obducten sobre el Proto-Caribe (Figura 2, $56 \mathrm{Ma}$ ), en ese proceso compresivo (Figura 2A, Beck, 1985a) ocurrido en el Paleoceno superior, se generan las primeras fallas tipo cabalgamiento, pliegues y depositación de olistolistos (Beck, 1985a). Producto de esta primera fase compresiva, rocas de alta presión y baja temperatura, junto con rocas que conforman el prisma de acreción, son cabalgadas sobre Suramérica, donde se

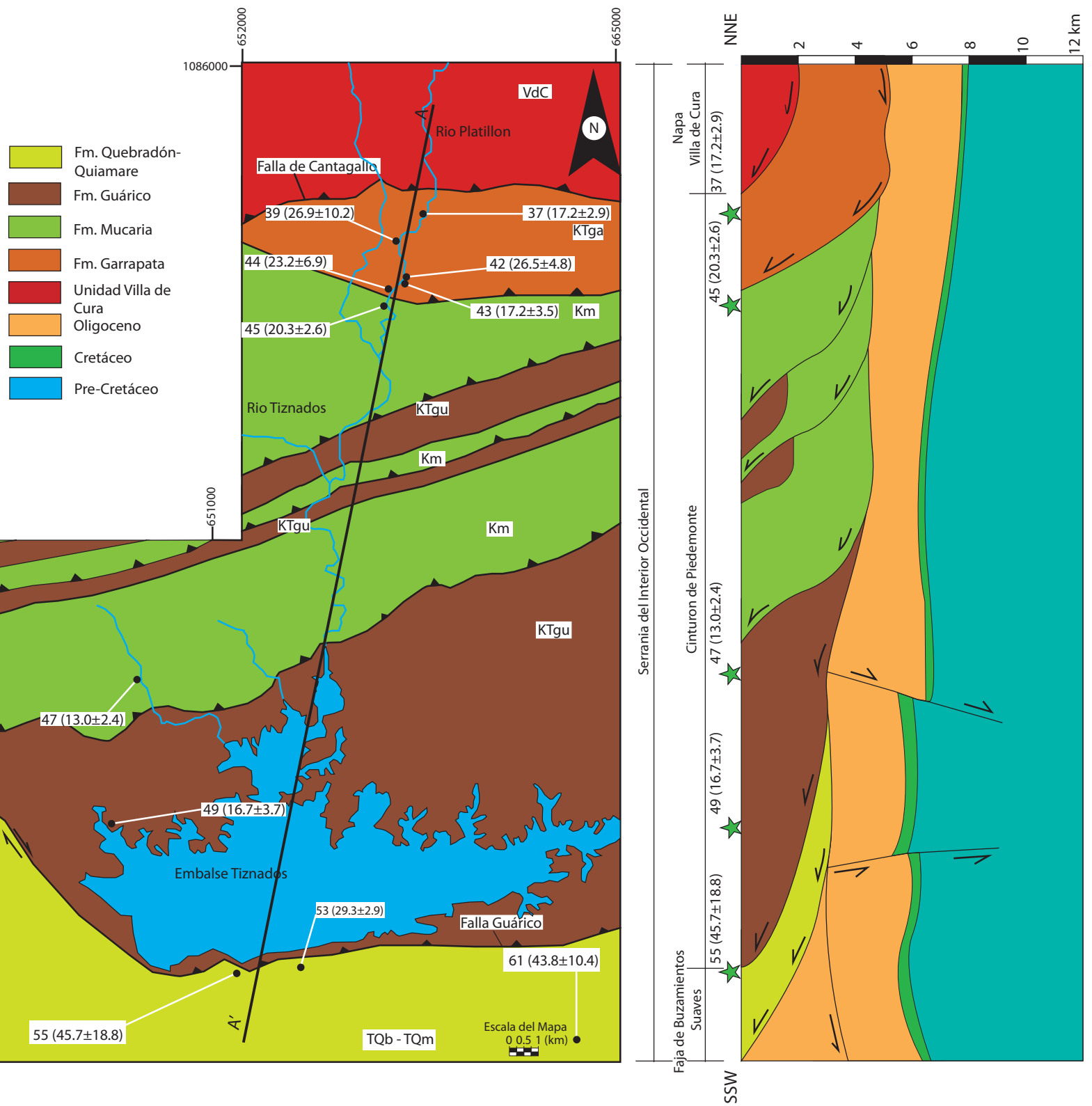

Figura 3 Mapa geológico del área de estudio en el que se encuentra la ubicación de la sección (A - A') el número externo corresponde con la nomenclatura de las muestras y el número entre paréntesis corresponde a la edades de trazas de fisión en apatito existentes y el error sobre esta (Tomado de Pérez de Armas, 2005), a la derecha se presenta una sección transversal considerada para el modelo termocinemático bidimensional (Fetkin, Almendral et al., 2015), en la que se representa la ubicación de las edades con estrellas verdes. 
depositan la parte basal de unidades turbidíticas como la Formación Guárico, la cual continúa en el Eoceno. De acuerdo con Stephan et al. (1980), en el Eoceno medio, ocurre el emplazamiento de las Napas de Lara en Venezuela noroccidental. En el Eoceno superior (41.2 a 33.9 Ma), se intensifica la transpresión entre las placas Caribe y Suramérica (Figura 2A), de acuerdo con Beck (1985a) esto explicaría una serie de cabalgamientos que sufren deformación por movimientos rumbo-deslizantes (Figura 2A). A finales del Eoceno, inicios del Oligoceno (Figura 2C, $33 \mathrm{Ma}$ ), ocurre el hundimiento de la corteza oceánica Proto-Caribe, lo cual favorece el avance de los materiales del arco que constituyen la Serranía del Interior, y no se descartan para ese momento volcanismos localizados debido a ese hundimiento.

Posiblemente en el Eoceno superior cambie la orientación del régimen de esfuerzos (Figura 2A), la transpresión podría haber resultado en la ruptura de gran parte de la litósfera para ese momento y se comienzan a crear pequeñas cuencas y zonas levantadas. En el Oligoceno superior a Mioceno inferior (27.2 a $15.97 \mathrm{Ma}$ ) en la Serranía del Interior, de acuerdo con las observaciones de Beck (1985a), podría haber ocurrido un proceso de extensión multidireccional, ocasionando la creación de fallas normales y la depositación de parte de la Formación Quebradón (Beck, 1985a). En el Mioceno medio (15.97 a $11.63 \mathrm{Ma}$ ), se incrementa nuevamente la fase compresiva, incrementando la transpresión lo cual resulta en la inversión de fallas normales, cabalgamientos y sistemas de plegamiento, produciendo el cierre definitivo de cuencas tipo flysch y arco (Urbani, 2012).

En el Mioceno superior (11.6 a 5.3 Ma), ocurre una nueva fase de extensión multidireccional, la cual genera distintas fallas normales, y localiza sistemas de grábenes. Desde el Mioceno al Cuaternario, continúa la compresión oblicua NO-SE que permite el desarrollo de importantes sistemas de fallas dextrales de ángulo alto como la falla de Oca-Ancón (Audemard, 1993), San Sebastián, La Victoria, Macuto, El Pilar, la transpresión facilita la exhumación de la Serranía del Interior y de otros sectores de la Cordillera de la Costa. Según
Beck (1985a), cambios locales en el patrón de esfuerzos y de ángulos en el sentido de la transpresión también podrían haber generado sistemas de fallas normales que resultan en la generación de importantes cuencas en la Cordillera de la Costa, como por ejemplo, la cuenca del Tuy (Audemard, 1984; 1997; Ollarves et al., 2004).

En resumen, se observan tanto en la Cordillera de la Costa como en la Serranía del Interior (Beck, 1985a; Avé-Lallemant y Sisson, 2005) al menos tres fases orogénicas. La primera, posiblemente fue sincrónica al evento de metamorfismo regional, aparentemente causada por procesos de zona de subducción, y probablemente ocurrió en el tiempo del Cretácico medio. La segunda deformación no fue metamórfica, ocurrió de forma continua en el Paleoceno-Eoceno, causada por la obducción de estas rocas contra el cratón sudamericano.

Finalmente, la tercera fase generada por un incremento en la transpresión desde finales del Oligoceno al Cuaternario.

\section{Materiales y métodos}

\subsection{BASE DE DATOS TERMOGRONOLÓGICOS}

Empleando diversos datos geocronológicos y termocronológicos existentes a lo largo de la Serranía del Interior (Kohn et al., 1984a; Sisson et al., 2005; Locke y Garver, 2005; Pérez de Armas, 2005; Flores et al., 2017) nos centramos en esta investigación en el sector comprendido entre la Serranía del Interior Occidental y la subcuenca de Guárico, y en particular, sobre aquella zona donde existen datos de termocronología por trazas de fisión en apatitos de Pérez de Armas (2005), principalmente por dos razones: 1) la existencia de secciones balanceadas estructurales, y 2) entre los datos termocronológicos se disponen de medidas de longitudes de trazas de fisión en apatito, lo cual es clave para la reconstrucción de historias tiempo-Temperatura. Pérez de Armas (2005) recolectó 30 muestras, a lo largo de cuatro transeptos regionales, a través de la Serranía del Interior occidental y la subcuenca de Guárico. El presente estudio 
se concentra en el transepto Platillón-Tiznados (Figura1E, Figura 3) donde existe un total de 11 datos termocronológicos.

\subsection{DATOS ESTRUCTURALES}

Se utilizan las secciones sísmicas del estudio de Pérez de Armas (2005) para realizar el balanceo estructural 2D, las cuales fueron construidas a partir de los perfiles de reflexión sísmica del año 1980 aportados por la empresa Petróleos de Venezuela (PDVSA), además de combinar datos de pozos y sismogramas sintéticos.

\subsection{DATOS SISMOLÓGICOS}

La base de datos sismológicos fue tomada de la Fundación Venezolana de Investigaciones Sismológicas (FUNVISIS), la cual comprende sismos históricos y actuales desde 1911 al 2020.

\section{Tratamiento de datos}

A continuación, se describe la metodología empleada para generar la historia termal de la parte central del norte de Suramérica, tomando en cuenta la relación del fallamiento, el espesor cortical, la sismicidad y el comportamiento termal en este sector (Figura 2D, 2F y 2G).

\subsection{GENERACIÓN DE SEGGIONES ESTRUGTURALES BALANCEADAS}

Se realizó el balanceo de secciones estructurales en el software $\mathrm{MOVE}^{\circledR}$, basado en el mapa geológico del estudio de Pérez de Armas (2005) y en la información estructural recopilada (Figura 3). El balanceo asume que el acortamiento de la cadena comienza a partir de los $56 \mathrm{Ma}$, generándose fallas de empuje que desplazan los materiales transportados por la Placa del Caribe, con un estilo tectónico mixto (piel gruesa y delgada), que constan de 4 secciones (Figura 4) (Eoceno (56 Ma), Mioceno (23 $\mathrm{Ma})$, Plioceno (5 Ma) y Reciente (0 Ma)), con un acortamiento total de $10 \mathrm{~km}$. La sección reciente denominadas "Fajas Tectónicas" por Bell (1968), comprende la Napa de Villa de Cura, el cinturón o faja piemontina y el cinturón de buzamientos suaves, correspondiente a la parte delantera de la subcuenca de Guárico, presentando napas y cinturones con una tendencia E-O. La sección reciente $(0 \mathrm{Ma})$, tiene una longitud de $34 \mathrm{~km}$ concordando con el tramo del transepto tomado para este estudio y la sección más antigua (56 Ma) tiene una longitud de $44 \mathrm{~km}$, el acortamiento se hace variable a través de las secciones basado en los eventos compresivos que sucedieron en cada uno de los tiempos, teniendo en cuenta que el menor acortamiento se presenta en el paso de la sección Plioceno a Reciente debido a la disminución en la ocurrencia de estos procesos compresivos.

\subsection{GENERAGIÓNDELMODELO TERMOGINEMÁTICO 2D}

Para la generación del modelo termocinemático 2D se utilizaron tres paquetes informáticos distintos: 1) $\mathrm{MOVE}^{\circledR}$ el cual permite introducir las distintas secciones balanceadas para diferentes tiempos geológicos, 2) FetKin prep (Carrillo et al., 2016) necesario para generar los vectores de velocidad e incluir la topografía actual y crear los archivos de entrada del código FetKin (Almendral et al., 2015b; Mora et al., 2015), 3) el código FetKin permite hacer la reconstrucción de la historia termocinemática incluyendo variables como flujo de calor, parámetros cinéticos (diámetro o Dpar y longitud promedio de trazas de fisión o mean track length -MTL-), predicción de edades a lo largo de la sección analizada y comparación con edades termocronológicas observadas.

Del modelo, se obtienen 3 gráficas de vectores de velocidad (Figura 5). En la gráfica de 56 a 23 $\mathrm{Ma}$, se observa un desplazamiento en el campo de velocidades de las fallas ubicadas en la parte norte de la sección; en la gráfica de 23 a 5 Ma, se observa un cabalgamiento más uniforme en sentido norte-sur, levantando las formaciones presentes; y en la gráfica de 5 a $0 \mathrm{Ma}$, se observa un cabalgamiento de formaciones cretácicas y oligocenas. 


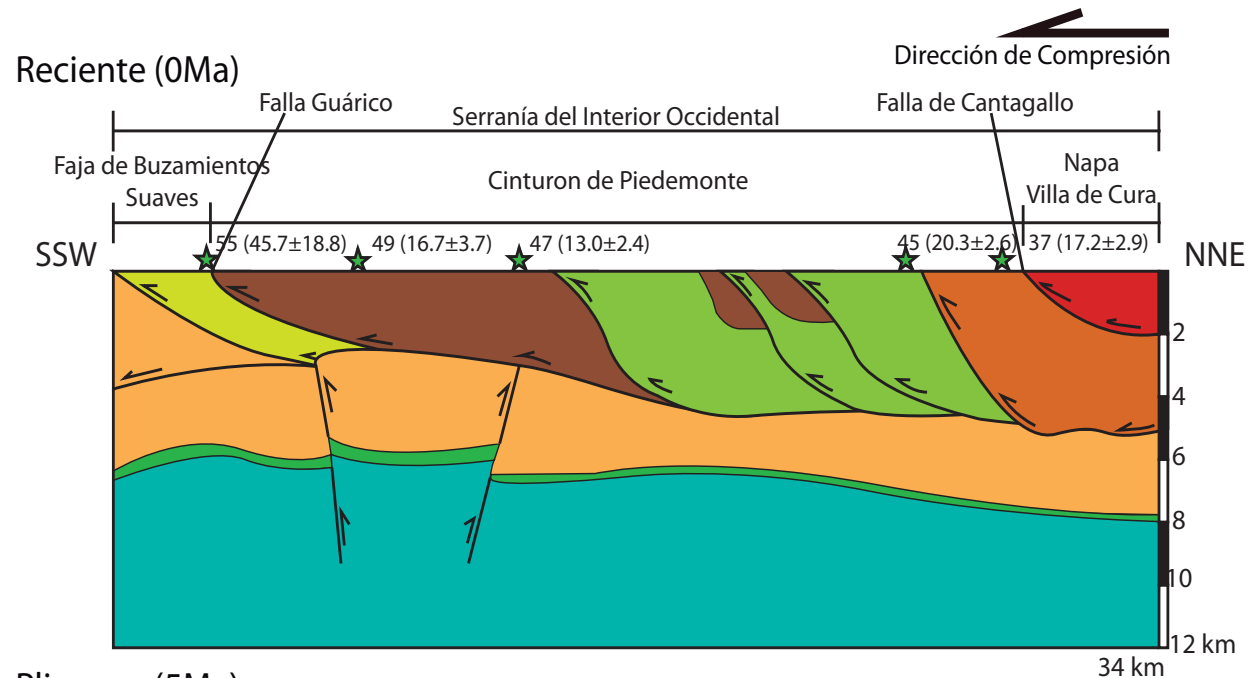

Plioceno $(5 \mathrm{Ma})$

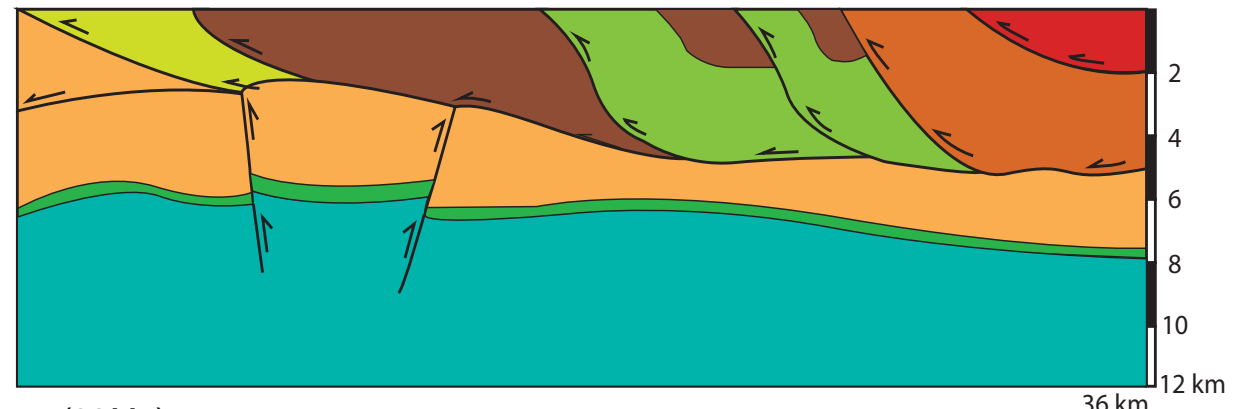

Mioceno (23Ma)

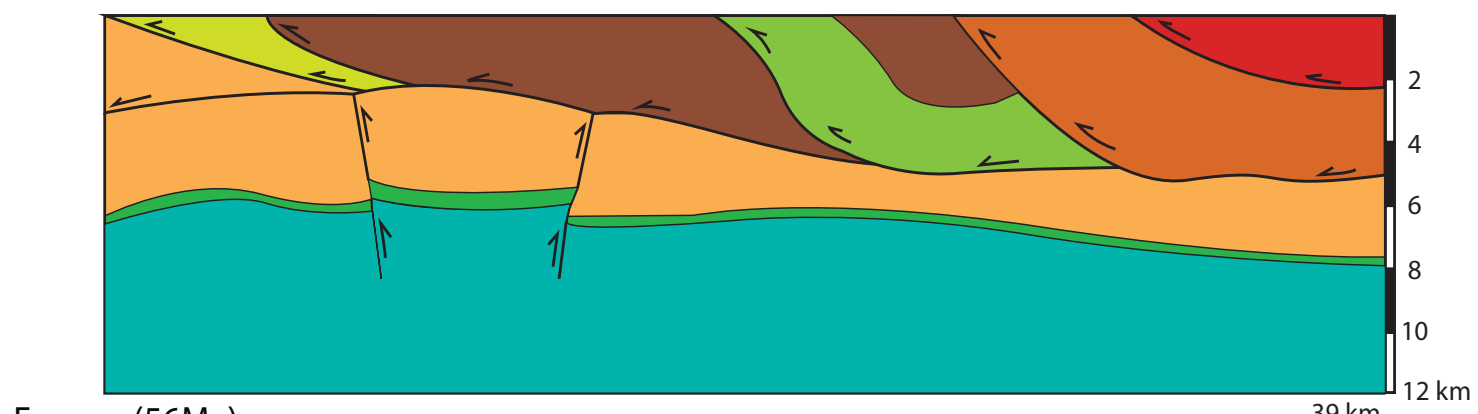

Eoceno (56Ma)

$39 \mathrm{~km}$

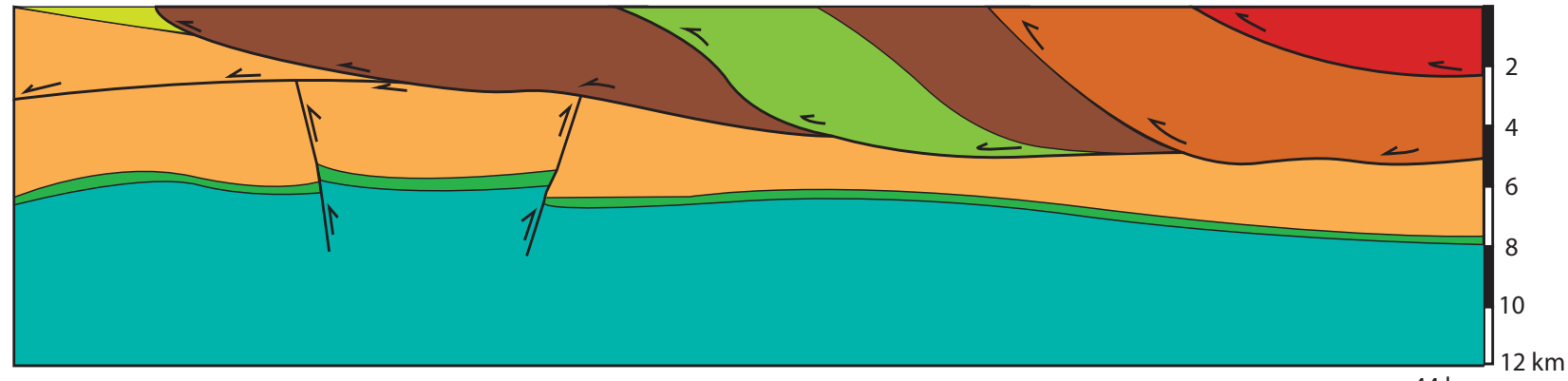

$44 \mathrm{~km}$

Figura 4 Secciones estructurales con un estilo tectónico mixto entre piel gruesa y delgada realizadas en el software MOVE son la base para el modelo termocinemático. Las unidades geológicas modeladas corresponden a las mismas mostradas en la figura 1. 
El modelo toma en cuenta la topografía actual, parámetros termales (mucho de los cuales se han considerado fijos), coordenadas o ubicación de las muestras, longitud de las trazas de fisión, Dpar y las tres secciones balanceadas mostradas en la Figura 4. Para generar el modelo termocinemático, se utilizan dos parámetros termales importantes:

1) Temperatura basal, la cual se refiere a la temperatura en la base del modelo, que para este caso es de $240^{\circ} \mathrm{C}$. Este dato se elige teniendo en cuenta que esta temperatura arroja un modelo más coherente con las edades termocronológicas obtenidas para este sector.

2) Tasa de producción de calor radiogénico, que es la propiedad física que define la cantidad de calor liberado en unidad de tiempo en una unidad de volumen de roca, generada por la desintegración de isótopos radiogénicos inestables $\left(\mathrm{U}^{238}, \mathrm{Th}^{232}\right.$ y $\mathrm{K}^{40}$ ), que para este caso es de $2 \mu \mathrm{W} /$ $\mathrm{m}^{3}$ debido a que es el dato que más se ajusta al modelo.

Con base en estos parámetros, se realizan modelos directos ("forward") cuyas predicciones son comparadas con las edades observadas para lograr un ajuste del modelo, lo cual se hace a través de la minimización de una función misfit, la cual se expresa como:

$$
\text { misfit }=\frac{1}{n} \sum_{j=1}^{n} \sqrt{\frac{t_{0_{i}}-t_{P i}}{\theta_{i}}}
$$

En esta ecuación $t_{o i}$ es la edad observada, $t_{p i}$ es la edad predicha por el modelo, $n$ es el número de datos termocronológicos y $\sigma_{i}$ es el error de la edad observada para cada dato $i$. El modelo termocinemático está conformado por: edades modeladas, longitud de trazas y datos de temperatura vs tiempo.

\subsection{GENERACIÓN DE MODELOS TERMALES INDIVIDUALES MEDIANTE TRAZAS DE FISIÓN EN APATITO}

De las 11 muestras del estudio de Pérez de Armas (2005), se seleccionaron sólo 5 de ellas (PFT-37,
PFT-45, PFT-47, PFT-49 y PFT-55; Figuras 1E y 3), basado en la variabilidad y rango de temperaturas que presentan, con las que se generaron de forma independiente las historias tiempo versus Temperatura en el software HeFTy versión 1.9.3 (Ketcham, 2017), con el fin de llevar a cabo una validación independiente de las historias tiempo-temperatura predichas por el modelo termocinemático 2D.

Para la generación de las historias termales, se toman en cuenta los datos termocronológicos como número de huellas espontáneas $\mathrm{N}$, número de huellas inducidas $\mathrm{Ni}$, longitud de trazas de fisión confinadas y diámetro de la traza de fisión (Dpar).

La longitud de trazas de fisión y el Dpar son conocidos como parámetros cinéticos y son extremadamente sensibles al gradiente geotérmico, flujo de calor, tiempo geológico y la presión a la cual está sometida la roca (Wagner y Van den Haute, 1992). El estimado de la edad de cada una de las muestras consideradas y otros datos son resumidos en la tabla 1.

Adicionalmente, se incorporaron los valores de reflectancia de vitrinita ( $\%$ Ro) para las formaciones geológicas que contaban con esta información, siendo la vitrinita un indicador de madurez termal. La reflectancia de la vitrinita registra la temperatura máxima que una roca ha experimentado desde su enterramiento. No puede ser considerada como un termocronómetro, ya que no proporciona una edad ni ninguna otra indicación directa del tiempo (Bermúdez y Flores, 2019).

Los valores de \%Ro para las formaciones geológicas estudiadas fueron tomados de Pérez de Armas (2005), y se incorporan con la finalidad de mejorar el modelo. Para obtener la historia termal de cada una de las muestras se utiliza el modelamiento inverso, creando restricciones o condiciones iniciales (cuadros azules ver figura 6), las cuales representan los principales pulsos tectónicos registrados en la Serranía del Interior Occidental.

El análisis e interpretación de las historias tiempo-temperatura para cada muestra permite 

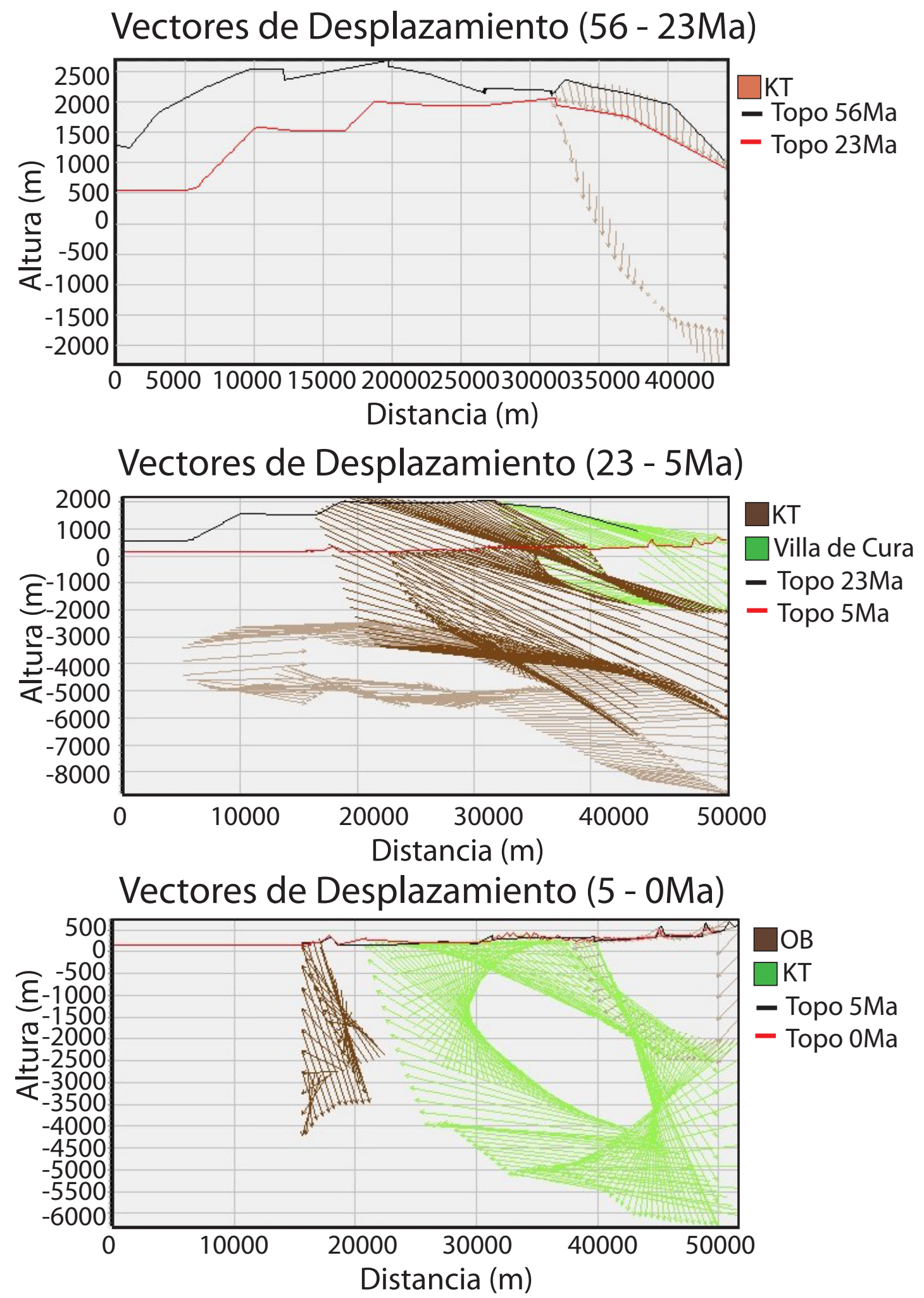

Figura 5 Vectores de desplazamiento del modelo de tectónica de piel gruesa basado en secciones de 56 Ma-23 Ma, 23 Ma-5 Ma y 5 Ma-0 
Tabla 1. Resumen de edades de trazas de fisión en apatito (Fuente: Pérez de Armas, 2005).

\begin{tabular}{|c|c|c|c|c|c|c|}
\hline Muestra & $\mathbf{N}_{\mathbf{s}}$ & $\mathbf{N}_{\mathbf{i}}$ & $\mathbf{N}_{\mathbf{d}}$ & Dpar & $\begin{array}{c}\text { Número de } \\
\text { cristales } \\
\text { analizados }\end{array}$ & $\begin{array}{c}\text { Edad Pooled } \\
(\mathbf{M a})\end{array}$ \\
\hline PFT-37 & 45 & 635 & 4349 & 1.76 & 16 & $17.2 \pm 2.9$ \\
\hline PFT-45 & 86 & 1017 & 4349 & 1.88 & 30 & $20.3 \pm 2.6$ \\
\hline PFT-47 & 35 & 647 & 4349 & 1.77 & 33 & $13.0 \pm 2.4$ \\
\hline PFT-49 & 24 & 344 & 4349 & 1.72 & 11 & $16.7 \pm 3.7$ \\
\hline PFT-55 & 7 & 44 & 4009 & 1.51 & 2 & $45.7 \pm 18.8$ \\
\hline
\end{tabular}

identificar los pulsos de enfriamiento asociados frecuentemente con el enfriamiento de los orógenos, bien sea por tectónica, incrementos en la tasa de erosión-denudación, o la interacción entre fenómenos climáticos y tectónicos. Mientras que los pulsos de calentamiento se relacionan generalmente con soterramiento asociados con fenómenos de subsidencia de cuencas, aumento de las tasas de depositación de formaciones sedimentarias, o aumentos en el gradiente geotérmico del área.
(Bassin et al. 2000; Laske et al., 2013). Con todos estos datos, se generaron los mapas mostrados en las figuras $1 \mathrm{D}, 1 \mathrm{~F}$ y $1 \mathrm{G}$. Dentro de la zona de estudio, se encuentran dos fallas importantes, la Falla Cantagallo al norte de la sección y la Falla Guárico al sur de la sección. Estas dos son fallas de empuje que han desplazado los materiales presentes en la zona. Según el mapa de sismicidad actual (Figura 1F), dichas fallas actualmente no presentan evidencias de actividad sísmica.

\subsection{CARACTERIZACIÓN DE LA AGTIVIDAD SISMOLÓGICA, RELACIÓN GON EL PATRÓN DE FALLAMIENTOS, FLUJO DE GALOR Y ESPESOR GORTIGAL AGTUAL}

Con la finalidad de reconocer la actividad de las fallas en la zona, se compilaron bases de datos de las principales fallas presentes en la zona (Audemard et al., 2000; French y Schenk, 2004; Hackley et al., 2005). También se emplearon los datos de sismicidad reciente de Venezuela para el período 1911 al 2013 de Bermúdez et al. (2013) y se completaron con datos del sitio web de FUNVISIS desde 2013 al 2020. Mientras que, para determinar el flujo de calor actual reportado en el área, se extrajeron datos del Instituto Tecnológico Venezolano el Petróleo S.A (INTEVEP) y Petróleos de Venezuela S.A (PDVSA, 2000), y de datos globales (Davies, 2013; Figura 1D). Los valores del espesor cortical fueron derivados del modelo GRUST 1.0

\section{Resultados}

\subsection{MODELADO NUMÉRICO DE HISTORIAS TERMALES MEDIANTE HEFTY}

A continuación, se describen las trayectorias tiempo-Temperatura resultantes para el modelo que mejor se ajusta a una inversión completa (Línea negra en las gráficas tiempo-Temperatura o t-T de la figura 7). La muestra PFT37 (Figura 6A) describe la historia termal de la Formación Garrapata en el área de estudio, la cual tuvo un proceso de depositación en un rango de edad de 89 a $86 \mathrm{Ma}$ con una temperatura de $35 \pm 20^{\circ} \mathrm{C}$. Luego se incrementó la cantidad de sedimentos sobre la formación como producto de la erosión de terrenos circundantes, obteniéndose una tasa de enterramiento de $1.48^{\circ} \mathrm{C} / \mathrm{Ma}$, en un periodo de edad de $52 \mathrm{Ma}$ hasta los $36 \mathrm{Ma}$, donde ocurre 
A
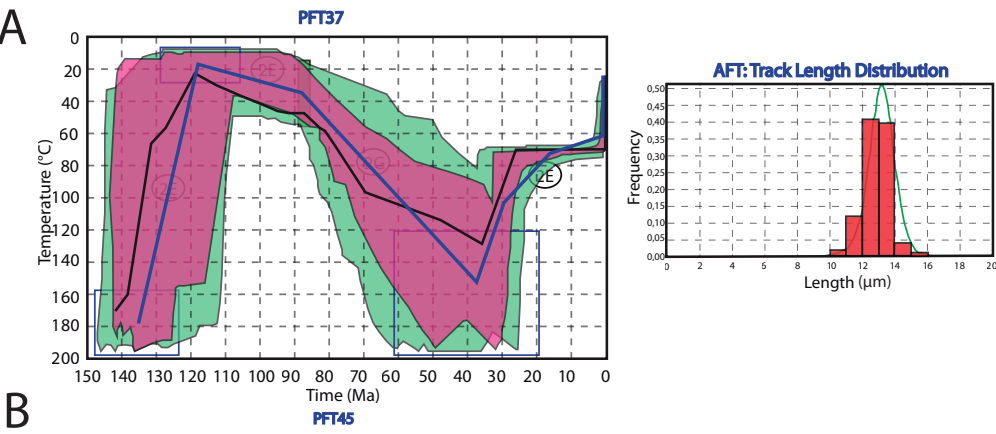

\begin{tabular}{|l|r|}
\hline AFT (O) & $24.2 \pm 6.6$ \\
\hline AFT (P) & 24.9 \\
\hline GOF AFT & 0.81 \\
\hline LTP (O) & $12.9 \pm 0.80$ \\
\hline LTP (P) & $13.2 \pm 0.91$ \\
\hline GOF LTP & 0.60 \\
\hline
\end{tabular}
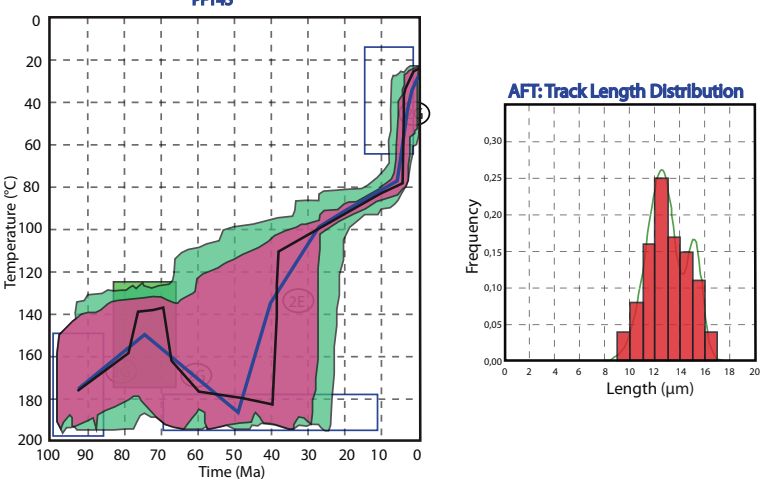

\begin{tabular}{|l|r|}
\hline AFT (O) & $18.9 \pm 4.2$ \\
\hline AFT (P) & 19.4 \\
\hline GOF AFT & 0.78 \\
\hline LTP (O) & $13.05 \pm 1.70$ \\
\hline LTP (P) & $13.02 \pm 1.62$ \\
\hline GOF LTP & 0.98 \\
\hline
\end{tabular}

\begin{tabular}{|l|r|}
\hline No. Muestra & PTF-45 \\
\hline Temperatura actual & $25^{\circ} \mathrm{C}$ \\
\hline Unidad Estratigráfica & Fm. Mucaria \\
\hline Edad Estratigráfica & $66 \mathrm{Ma}$ \\
\hline Tiempo de Temperatura pico & $40 \mathrm{Ma}$ \\
\hline $\begin{array}{l}\text { Tiempo del Evento de } \\
\text { Enfriamiento }\end{array}$ & $40 \mathrm{Ma}$ \\
\hline
\end{tabular}

C
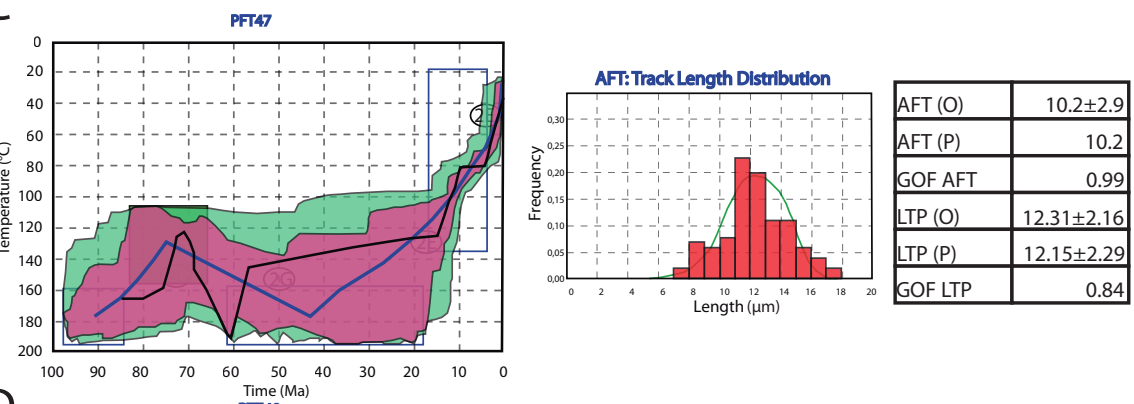

\begin{tabular}{|l|r|}
\hline No. Muestra & PTF-47 \\
\hline Temperatura actual & $25^{\circ} \mathrm{C}$ \\
\hline Unidad Estratigráfica & Fm. Mucaria \\
\hline Edad Estratigráfica & $66 \mathrm{Ma}$ \\
\hline Tiempo de Temperatura pico & $61 \mathrm{Ma}$ \\
\hline $\begin{array}{l}\text { Tiempo del Evento de } \\
\text { Enfriamiento }\end{array}$ & $61 \mathrm{Ma}$ \\
\hline
\end{tabular}

D
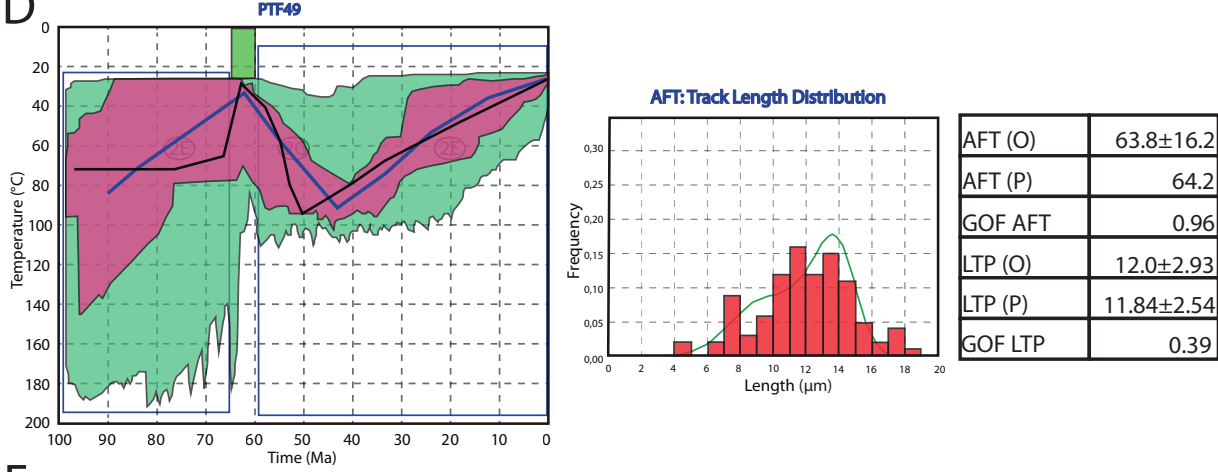

\begin{tabular}{|l|r|}
\hline No. Muestra & PTF-49 \\
\hline Temperatura actual & $25^{\circ} \mathrm{C}$ \\
\hline Unidad Estratigráfica & Fm. Guárico \\
\hline Edad Estratigráfica & $60 \mathrm{Ma}$ \\
\hline Tiempo de Temperatura pico & $52 \mathrm{Ma}$ \\
\hline $\begin{array}{l}\text { Tiempo del Evento de } \\
\text { Enfriamiento }\end{array}$ & $52 \mathrm{Ma}$ \\
\hline Easy Ro (\% Reflectancia) (O) & $0.64 \pm 0.01$ \\
\hline Easy Ro (\% Reflectancia) (P) & $>0.55$ \\
\hline GOF Easy Ro (\% Reflectancia) & \\
\hline
\end{tabular}

$\mathrm{E}_{0}$ PTF55
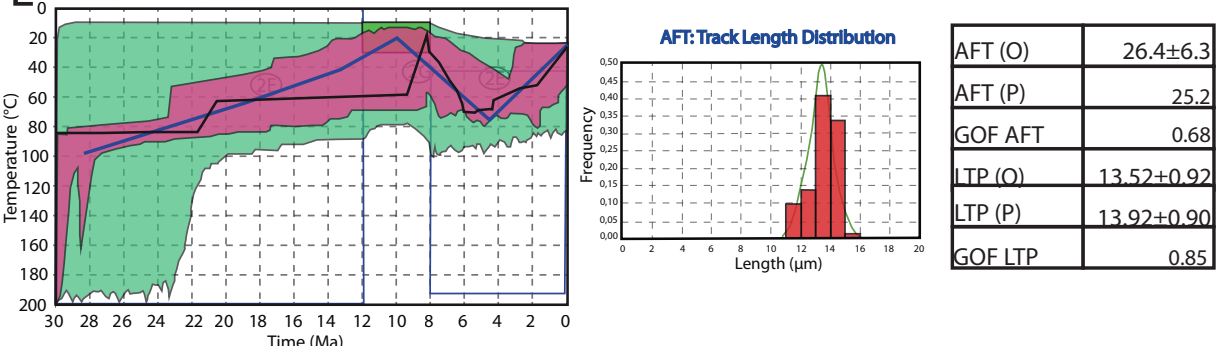

Figura 6 Historia termal de las muestras A) PFT-37, B) PFT-45, C) PFT-47, D) PFT-49 y E) PFT-55, realizadas en el Software HeFTy. 
el soterramiento máximo a una temperatura de $127^{\circ}$ C. Después experimenta un proceso de enfriamiento con una tasa de $2.83^{\circ} \mathrm{C} / \mathrm{Ma}$ durante un periodo de tiempo de $36 \mathrm{Ma}$ hasta llegar a la superficie en el tiempo actual (0 Ma) en el que presenta una temperatura ambiente de $25^{\circ} \mathrm{C}$. La distribución de longitud de trazas es unimodal $(12.90 \pm 0.80 \mu \mathrm{m})$, lo que sugiere la existencia de un solo evento termal y un enfriamiento lento.

La muestra PFT45 (Figura 6B) describe la historia termal de la Formación Mucaria en el área de estudio, la cual se generó en un rango de edad de 83 a $66 \mathrm{Ma}$, en la que se encontraba enterrada a una temperatura de $150 \pm 25^{\circ} \mathrm{C}$. Luego, en un periodo de tiempo relativamente corto, hubo un incremento en la sedimentación sobre la formación que condujo a un mayor enterramiento a los $40 \mathrm{Ma}$ con una temperatura máxima de soterramiento de $185^{\circ} \mathrm{C}$, realizándose este enterramiento a una tasa de $1.53^{\circ} \mathrm{C} / \mathrm{Ma}$, durante un intervalo de tiempo de $30 \mathrm{Ma}$. Por procesos tectónicos anteriores, ocurre un enfriamiento muy rápido con una tasa de $74^{\circ} \mathrm{C} / \mathrm{Ma}$, lo que equivale a un soterramiento con una tasa superior a los $2 \mathrm{~km} /$ $\mathrm{Ma}$, seguido por un proceso que registra una tasa de enfriamiento de $0.88^{\circ} \mathrm{C} / \mathrm{Ma}$ en un intervalo de tiempo de $34 \mathrm{Ma}$. Esto sugiere una desaceleración en la tasa de enfriamiento, para luego registrar un último pulso de enfriamiento con una tasa de $11^{\circ} \mathrm{C} / \mathrm{Ma}$ que muestra un incremento en los procesos tectónicos compresivos y de erosión que sufrió la roca. Se presenta una distribución de longitud de trazas unimodal $(13.05 \pm 1.7 \mu \mathrm{m})$, lo que sugiere que solo existió un evento termal y un enfriamiento más lento.

La muestra PFT47 (Figura 6C) describe y complementa la historia termal de la Formación Mucaria, en la que se evidencia que la formación tiene casi el mismo proceso termal que el derivado de la muestra PTF45, pero con variaciones en los tiempos de ocurrencia. Lo anterior, se puede deber probablemente a la acción de las fallas que separan esta formación y la ponen en contacto con la Formación Guárico, teniendo en cuenta que esta muestra fue tomada más al sur que la muestra PFT45; siendo otra posible explicación la posición de la muestra con respecto a su migración sobre el cabalgamiento. Además, reafirma la ocurrencia de un proceso diacrónico en la zona. Luego de la depositación de la formación, se presenta un proceso de sedimentación sobre ésta, que conlleva al enterramiento de esta formación con una tasa de calentamiento o soterramiento de $7.5^{\circ} \mathrm{C} / \mathrm{Ma}$ en un periodo de tiempo de $10 \mathrm{Ma}$, en el que alcanza un soterramiento máximo con una temperatura de $196^{\circ} \mathrm{C}$, para luego ocurrir un enfriamiento rápido a una tasa de $12^{\circ} \mathrm{C} / \mathrm{Ma}$, en un periodo de $4 \mathrm{Ma}$, seguido de un proceso de enfriamiento más lento con una tasa de $0.52^{\circ} \mathrm{C} /$ $\mathrm{Ma}$, en un periodo de tiempo de $42 \mathrm{Ma}$, lo que indica que este proceso fue más lento y finalmente la formación sufre un proceso de enfriamiento para llegar a temperatura ambiente en superficie, con una tasa de $6.46^{\circ} \mathrm{C} / \mathrm{Ma}$, en un periodo de tiempo de $15 \mathrm{Ma}$. Se observó una distribución de longitud de trazas unimodal $(12.31 \pm 2.16 \mu \mathrm{m})$, que sugiere que solo existió un evento termal y un enfriamiento un poco lento.

La muestra PFT49 (Figura 6D) describe la historia termal de la Formación Guárico, la cual tuvo un proceso de depositación en un rango de edad de 65 a $60 \mathrm{Ma}$ con una temperatura de 20 $\pm 20^{\circ} \mathrm{C}$. Posteriormente, ocurre el proceso de sedimentación sobre la formación en un periodo de tiempo relativamente corto lo que conlleva al soterramiento de la roca con una tasa de enfriamiento de $5.23^{\circ} \mathrm{C} / \mathrm{Ma}$ en un rango de tiempo de $13 \mathrm{Ma}$, obteniendo un soterramiento máximo a una edad de $52 \mathrm{Ma}$ con una temperatura de $95^{\circ} \mathrm{C}$, seguido de un enfriamiento de la roca con una tasa más lenta de $1.40^{\circ} \mathrm{C} / \mathrm{Ma}$ en un periodo de tiempo de $50 \mathrm{Ma}$, hasta llegar al tiempo actual con una temperatura ambiente de $25^{\circ} \mathrm{C}$. Se presenta una distribución de longitud de trazas bimodal (12.00 $\pm 2.93 \mu \mathrm{m}$ ), que sugiere la existencia de dos eventos termales y un enfriamiento lento.

La muestra PFT55 (Figura 6E) describe la historia termal de las formaciones Quebradón y Quiamare, que en esta parte de la zona de estudio se consideran la misma unidad formacional 
(Pérez de Armas, 2005). Éstas son las rocas más jóvenes de la zona y tienen una edad de depositación de 12 a 8 Ma con una temperatura de $20 \pm 10^{\circ} \mathrm{C}$. Posterior a su depositación, se presentó un proceso de sedimentación sobre la formación que produjo un soterramiento y el calentamiento máximo de la roca con una tasa de $26^{\circ} \mathrm{C} / \mathrm{Ma}$, alcanzando una temperatura de $72^{\circ} \mathrm{C}$, en un lapso de $2 \mathrm{Ma}$. La formación luego se exhuma hasta el tiempo actual con una tasa de enfriamiento de $7.5^{\circ} \mathrm{C} / \mathrm{Ma}$, siendo este un proceso de enfriamiento relativamente rápido. Se observó una distribución de longitud de trazas unimodal (13.52 $\pm 0.92 \mu \mathrm{m})$, que sugiere que solo existió un evento termal y un enfriamiento rápido. Finalmente es importante aclarar que las historias termales terminan en el tiempo $0 \mathrm{Ma}$ (presente) y como condición sobre la temperatura se toma la temperatura ambiente de $25^{\circ} \mathrm{C}$ en ese tiempo.

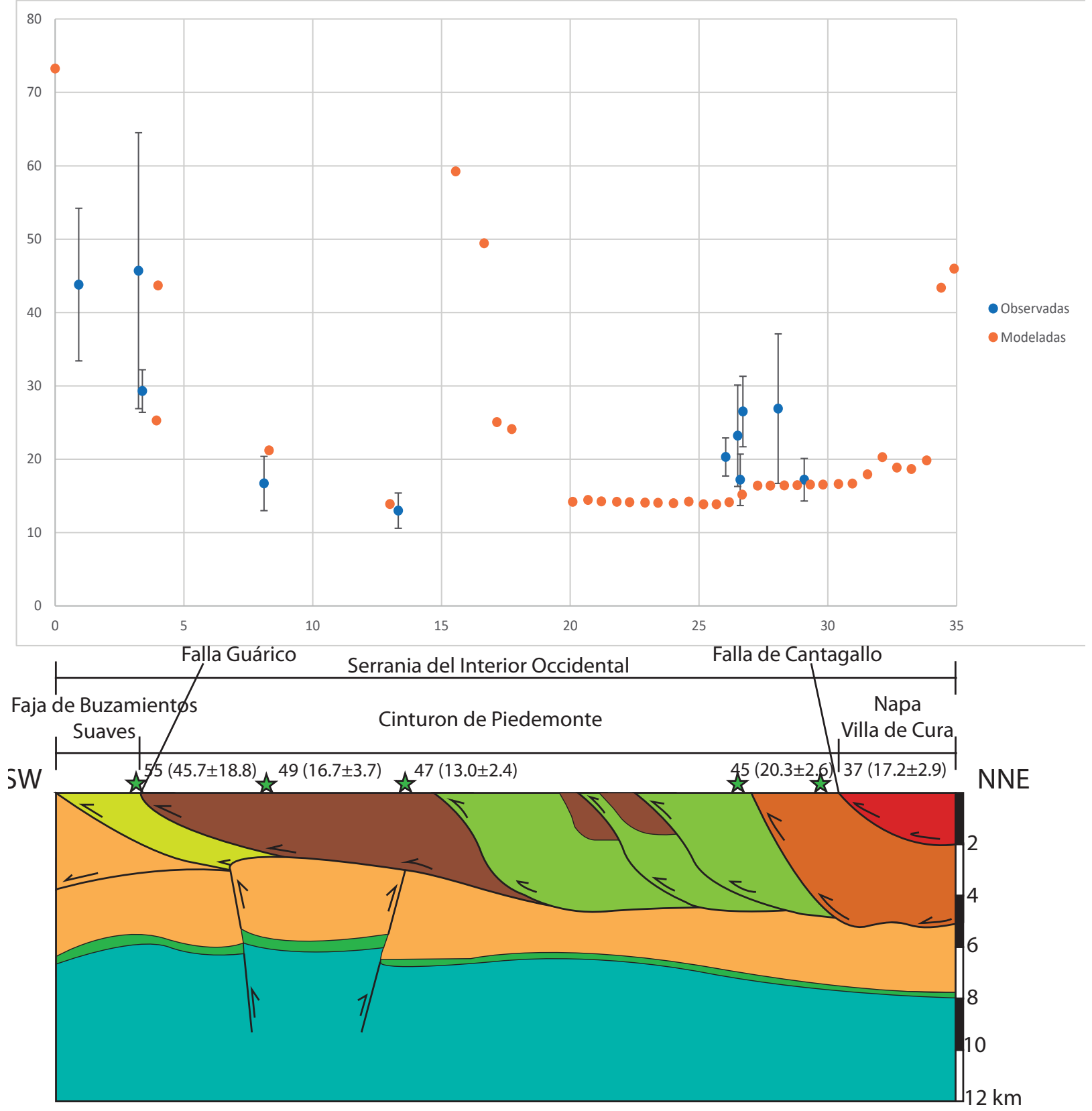


Las historias tiempo-temperatura predichas, se clasifican de aceptables a buenas, basado en un criterio estadístico que mide la cercanía entre variables predichas y observadas. Aquellas consideradas como buenas, son las que poseen un valor GOF (Prueba de bondad de ajuste entre observación y predicción) cercano a 1, entre estas variables destacan: edad, longitud de traza y valores promedios de reflectancia de vitrinita ( $\%$ Ro). Las pruebas de bondad de ajuste (goodness of fit-GOF-) indica la probabilidad de fallar la hipótesis nula, o lo que equivale a decir que las predicciones y las edades no son cercanas (Ketcham, 2017).

\subsection{VALIDAGIÓN DEL MODELO TERMOGINEMÁTICO}

Para validar el modelo termocinemático, se realizan dos procedimientos: 1) Comparar las edades modeladas y las edades observadas y 2) comparar las historias termales obtenidas del modelo termocinemático asumiendo un modelo tectónico mixto entre piel gruesa y piel delgada, con las historias modeladas independiente de cada uno de los datos termocronológicos. Para el primer procedimiento se toma en cuenta la función misfit expresada en la ecuación 1, dando como resultado para el modelo un misfit promedio de 1.23, lo que representa una cercanía entre edades modeladas y observadas (Figura 7).

Para el segundo procedimiento, se realizan 4 gráficas donde se comparan las historias termales tiempo-Temperatura obtenidas por trazas de fisión en apatito (historia t-T predicha), con las historias derivadas del modelo termocinemático. Estos modelos se ubicaron a lo largo de la sección modelada en la Figura 8 para facilitar el entendimiento de los procesos tectónicos que pudieron actuar de norte a sur en la zona de estudio. La muestra PFT55 de la Formación Quiamare no se compara debido a que el modelamiento termocinemático no arroja valores de soterramiento con edades tan jóvenes como la que indica esta muestra (5 Ma).

Las curvas azules de la parte superior de la Figura 8 corresponden a la historia termal de mejor ajuste de cada una de las muestras derivadas del software HeFTy, mientras que las curvas naranjas corresponden a las trayectorias t- $\mathrm{T}$ derivada de FetKin en el cual todas las muestras son modeladas al mismo tiempo tomando en cuenta parámetros cinemáticos de las fallas (velocidad, flujo de calor, y acortamiento de la sección). Se observa en esta figura que las curvas azules llegan hasta la superficie mientras que las curvas naranjas no lo hacen completamente, aunque las tendencias en soterramiento y enfriamiento pudieran coincidir. Éstas no llegan completamente a la superficie en el modelo FetKin porque no contempla la erosión, siendo el mecanismo que le permite a la roca quedar expuesta. Una manera de solventar esto sería aumentar la tasa de acortamiento, o incluir un módulo de erosión en el software.

El modelo termocinemático muestra una historia termal en la que se aprecian 3 pulsos tectónicos de enfriamiento y/o exhumación considerable comprendidos entre $\sim 48$ a $40 \mathrm{Ma}, \sim 40$ a $23 \mathrm{Ma}$ y $\sim 23$ a 0 Ma, mientras que las historias obtenidas por termocronología por trazas de fisión en apatito, muestra una historia termal en la que se aprecian 4 pulsos tectónicos de enfriamiento comprendidos entre $\sim 48$ a $40 \mathrm{Ma}, \sim 40$ a $28 \mathrm{Ma}, \sim 28$ a $15 \mathrm{Ma}$ y $\sim 15$ a 0 Ma. De lo anterior, se observa que el modelo termocinemático no detecta el pulso de enfriamiento comprendido entre $\sim 15$ a $0 \mathrm{Ma}$, posiblemente requiriéndose considerar anteriormente otras secciones balanceadas en este intervalo.

Con el modelamiento termocinemático se reproducen datos hasta una temperatura de $156^{\circ} \mathrm{C}$, debido posiblemente a la profundidad del modelo estructural y por tener un estilo tectónico mixto. En el modelo se resalta que está muy marcado el pulso tectónico que empezó en el Oligoceno medio y llegó hasta comienzos del Mioceno.

\section{Discusión}

\subsection{ACTIVIDAD DE FALLAS, SISMIGIDAD Y FLUJO DE GALOR}

Según la información extraída de las figuras 1 y 8 , se puede afirmar que, aunque hacia la parte norte (Serranía del Litoral) fuera de la zona de estudio, hay una significativa actividad sísmica con magnitudes 


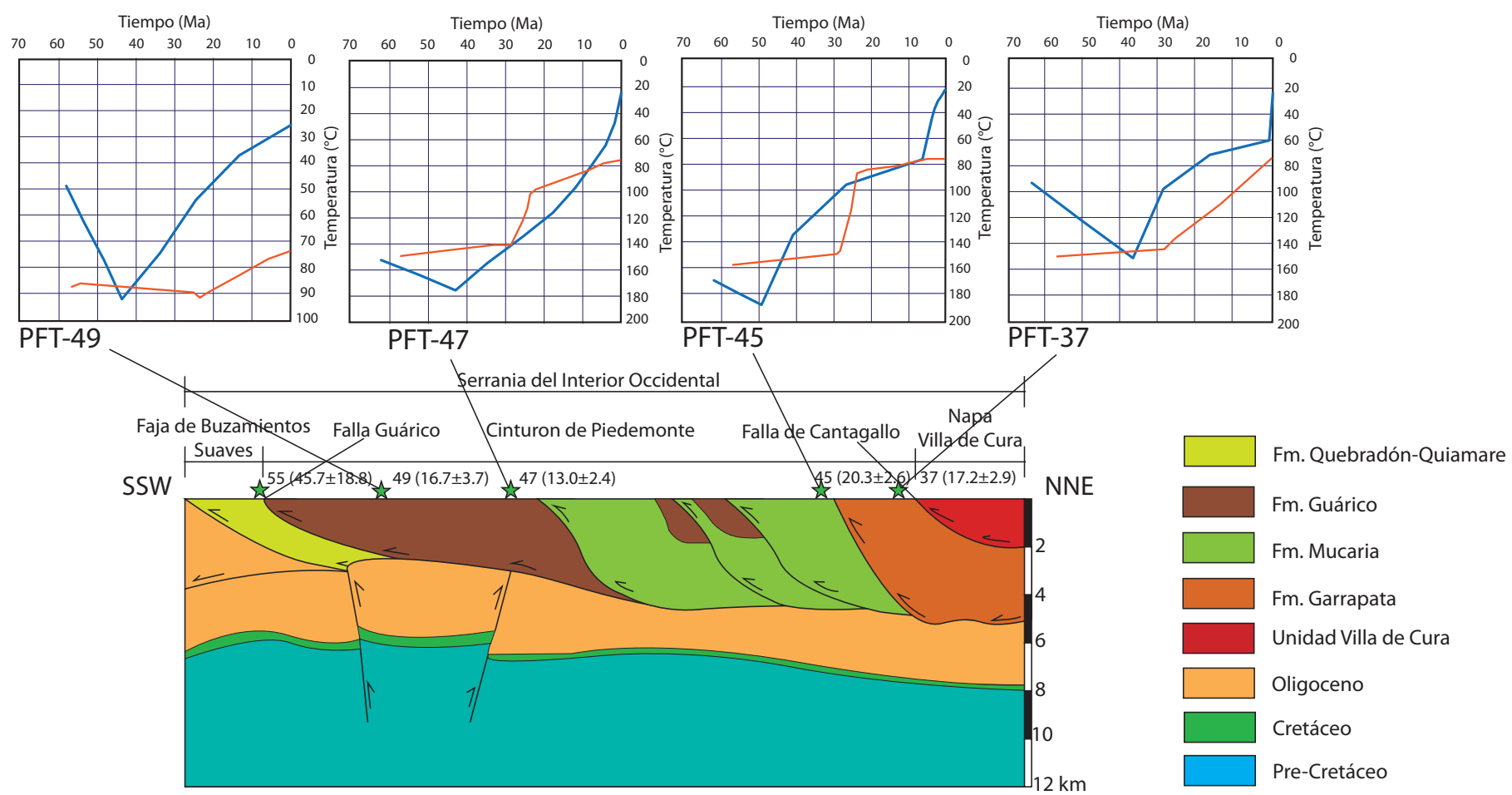

Figura 8 Comparación entre historias tiempo-Temperatura observadas (HeFTy, línea azul) y modeladas (FetKin, línea naranja) para cada una de las muestras cuya ubicación se encuentra en la sección transversal, acompañada de la estratigrafía.

que van desde Mw 2 a 3.5, la zona de estudio no se ve afectada por sismos ni hay actividad de fallamiento reciente. La baja sismicidad y actividad de fallas se relaciona con un flujo de calor intermedio para esta zona (Figura 8), observando que las zonas donde hay mayor actividad de las fallas coinciden con un mayor flujo de calor.

Este último puede ser afectado por procesos orogénicos, intrusiones, erosión, sedimentación, depositación y deformación de la corteza (Musset y Khan, 2000), lo que indicaría que en la zona de estudio posiblemente se presenten estos procesos formadores de relieve que generan un flujo de calor medio. Tales mecanismos producen cambios de espesor en la litósfera y variación de la concentración de elementos radiactivos, lo que influye en la cantidad de flujo de calor. Es importante mencionar que se ha observado importantes concentraciones de radón en los sistemas hidrotermales del norte de Venezuela, lo cual demostraría no sólo la importante actividad sísmica de la zona, sino también la contribución de elementos radioactivos que podrían incrementar el flujo de calor (Horváth et al., 2000).
La alta sismicidad reportada al norte de Suramérica, específicamente a lo largo de las Montañas del Caribe en Venezuela se encuentra relacionada con la zona de interacción entre las placas Caribe y Suramericana (Audemard et al., 2005, 2006; Liuzzi et al., 2006; Palma et al., 2010; Audemard y Castilla, 2016), lo cual se evidencia en los mapas de actividad sísmica y mecanismos focales (Audemard et al., 2005) y flujo de calor (Figura 8), donde la mayor actividad y flujo radica en la zona de convergencia entre estas dos placas.

\subsection{INTERPRETAGIONES DE LAS HISTORIAS TERMALES (HEFTY)}

$\mathrm{Al}$ interpretar los pulsos tectónicos relacionados con el soterramiento de las rocas, hasta llegar a su enterramiento máximo y luego su exhumación hasta el tiempo actual, se observa que las rocas sufrieron su mayor enterramiento en un rango de edades de aproximadamente 60 a $40 \mathrm{Ma}$, es decir, en el Paleoceno tardío a Eoceno medio, época en la que la fase de margen pasivo fue interrumpida por la progresiva colisión de oeste a este del arco del Caribe con el margen pasivo en la región de 
Tabla 2. Comparación entre edades estratigráficas, observadas y modeladas (Fuente: Elaboración propia).

\begin{tabular}{|l|c|c|c|}
\hline \multicolumn{1}{|c|}{ Formación } & $\begin{array}{c}\text { Edad } \\
\text { estratigráfica }\end{array}$ & $\begin{array}{c}\text { Edad } \\
\text { observada }\end{array}$ & $\begin{array}{c}\text { Edad } \\
\text { Modelada }\end{array}$ \\
\hline Fm. Guárico & $60-65$ & 16.7 & 43.37 \\
\hline Fm. Garrapata & $89-86$ & 23.2 & 14.04 \\
\hline Fm. Mucaria & $83-66$ & 13.0 & 22.83 \\
\hline Fm. Quebradón - Quiamare & $12-8$ & 45.7 & 20.91 \\
\hline
\end{tabular}

la cuenca de Maracaibo (Figura 2; e.g., Escalona y Mann, 2011). Debido a que la zona sufre un proceso de convergencia diacrónica de oeste a este, se observa cómo estas rocas pudieron estar afectadas en este rango de tiempo por los procesos que ocurrían más al oeste de la zona de estudio.

Luego de este enterramiento máximo, comienzan los pulsos de exhumación desde el Oligoceno al presente que están relacionados con la transpresión generada por la colisión entre las placas Caribe y Suramericana (Stéphan et al., 1980; Pindell, 1993; Audemard y Audemard, 2002; Audemard et al., 2005; Audemard, 2009; Pindell y Kennan, 2009).

\subsection{INTERPRETACIONES DEL MODELADO TERMOGINEMÁTICO (FETKIN)}

Las temperaturas de soterramiento del modelo sugieren una deformación más intensa en el norte de la sección, desde la Serranía del Interior occidental hasta el cinturón de buzamientos suaves, siendo esto concordante con un cinturón fallado y plegado con disminución progresiva de la deformación hacia el sur. Esta deformación se traduce en un acortamiento y compresión de las rocas (Figura 8), además indica una disminución hacia el sur del flujo de calor, ya que, en el sector norte de la sección se tiene un espesor de la corteza más delgado (Figura 1G), basado en los datos del modelo CRUST 1.0 (Bassin et al. 2000; Laske et al., 2013), generando un mayor flujo de calor.

Las edades obtenidas con trazas de fisión en apatito (edad observada) y por modelado termocinemático (edad modelada) son más jóvenes que las edades estratigráficas de las unidades muestreadas (Tabla 2), lo que sugiere un posible evento de soterramiento a finales del Oligoceno y su posterior exhumación.

En general, las historias termales sugieren una elevación y erosión de la Serranía del Interior occidental desde el Eoceno temprano, observándose un fallamiento activo desde el Oligoceno medio al Mioceno temprano, luego disminuye la tasa de exhumación indicando un proceso compresivo menos intenso. El comienzo de la exhumación y enfriamiento de las rocas en el Eoceno se debió a la colisión de la placa del Caribe y el arco de islas volcánicas de Antillas Holandesas con el anterior margen pasivo suramericano, que también produjo un acortamiento de la litósfera y esto se asocia a un fallamiento de tipo transpresivo.

Para la calibración del modelo termocinemático se utilizaron dos parámetros termales (temperatura basal y tasa de producción de calor radiogénico). A continuación, se interpretan los valores elegidos para el modelo. La temperatura basal es la temperatura en la base del modelo, la cual está en función del gradiente geotérmico, que para esta zona es de $27^{\circ} \mathrm{C} / \mathrm{km}$ según estudios realizados en el campo Yucal-Placer (Daal y Lander, 1993), identificando que el modelo llega a reproducir datos hasta una profundidad de $\sim 9$ $\mathrm{km}$, lo que indica que el modelo es profundo, debido a la tectónica de piel gruesa. La tasa de producción de calor radiogénico se toma como una función exponencial de la profundidad, lo 
que ha tenido un uso y aceptación generalizado desde que fue propuesto por primera vez por Lachenbruch (1968), pero representa, en el mejor de los casos, una gran simplificación del perfil de producción de calor real en cualquier entorno geológico particular (Ketcham, 1996). Este estudio se acoge a esta simplificación, pero, basado en estudios como el de Brady et al. (2005) o Kumar y Reddy (2004), que han analizado la producción de calor radiogénico como una función de la profundidad, obteniendo modelos empíricos con base en valores determinados con termobarometría y datos radioelementales respectivamente, propone realizar un estudio similar en la zona para corroborar el dato de producción de calor radiogénico obtenido mediante el modelado termocinemático, que es de $2 \mu \mathrm{W} / \mathrm{m}^{3}$, lo que indica que las rocas pudieron haber alcanzado profundidades de hasta $\sim 8 \mathrm{~km}$ de enterramiento.

$\mathrm{Al}$ obtener la profundidad de soterramiento (z) y la tasa de elevación (Ur) (Tabla 3), para las muestras modeladas por FetKin se identifica que el modelo termocinemático llega a analizar hasta una profundidad de soterramiento de hasta $\sim 5$ $\mathrm{km}$; y la tasa de exhumación llega hasta 0.16 $\mathrm{mm} / \mathrm{Ma}$. Se resalta que las muestras más al norte (PFT-37 y PFT45) arrojan los mayores valores, siendo este sector el más afectado por los procesos compresivos.

La profundidad de soterramiento (z) es calculada como (Ecuación 2):

$$
Z=\frac{\operatorname{Tmax}-T s u p}{G}
$$

Donde

$z=$ profundidad máxima del soterramiento

Tmáx = temperatura máxima del soterramiento

$G=$ gradiente geotérmico

Tsup $=$ temperatura actual en superficie $\left(25^{\circ} \mathrm{C}\right)$

Así la tasa de elevación (columna de rocas r) es calculado como (Ecuación 3):

$$
U_{r}=\frac{z}{t_{c}}
$$

En esta última:
$U_{r}=$ tasa de levantamiento de la columna de rocas

$z=$ profundidad de soterramiento

$t_{c}=$ edad del evento de enfriamiento

Observando los pulsos tectónicos obtenidos mediante termocinemática o termocronología, se aprecia que el modelo termocinemático tiene un buen comportamiento en comparación con el modelo inverso de termocronología de baja temperatura (trazas de fisión en apatito) y, aunque no se observe el pulso tectónico comprendido entre 15 a $0 \mathrm{Ma}$, los modelos son coherentes entre sí de manera general, ya que representan una historia de enfriamiento continuo a partir del Eoceno medio.

En la presente investigación, se relacionaron los pulsos tectónicos de enfriamiento más grandes ocurridos en la zona producto de la interacción entre las placas del Caribe y Suramérica (Figura 9). La inversión de la cuenca resultante de la contracción horizontal puede dar lugar a la exhumación del basamento por la reactivación combinada de fallas normales preexistentes y la iniciación de nuevas fallas inversas. En la mayoría de los orógenos, las estructuras de piel gruesa y de piel fina se producen y evolucionan con un patrón en el que el apilamiento de napas se propaga hacia afuera y hacia abajo (Beck, 1985a). Durante el Eoceno medio, la placa del Caribe avanza hacia el este, provocando el emplazamiento de las Napas de Lara, las cuales sobrecabalgaron a un margen pasivo (Stephan et al., 1990). En el Oligoceno medio a Mioceno temprano la placa del Caribe continúa su movimiento hacia el este sugiriendo un levantamiento causado por la subducción inicial de la placa del Caribe a lo largo del cinturón deformado del Caribe Sur en el noroeste (Taboada et al., 2000), dando también como resultado el emplazamiento final de las Napas de Lara (Sisson et al., 2005), y originando fallas de empuje que ocasionaron la migración hacia el sureste de los terrenos alóctonos transportados por la placa del Caribe. En el Mioceno continua la subducción de la placa del Caribe debajo de la placa Sudamericana impulsando la elevación final de las cadenas montañosas en especial de la Cordillera de la Costa y de la Serranía del Interior 
Tabla 3. Profundidad de soterramiento y tasa de exhumación considerada en el modelo termocinemático.

\begin{tabular}{|c|c|c|}
\hline \multirow{2}{*}{ Muestra } & \multicolumn{2}{|c|}{ Modelo Termocinemático } \\
\cline { 2 - 3 } & Profundidad de & Tasa de \\
& soterramiento (z) & exhumación (Ur) \\
\hline PFT37 & $(\mathrm{km})$ & 0.16 \\
\hline PFT45 & 4.48 & \\
\hline PFT47 & 4.85 & 0.09 \\
\hline PFT49 & 4.48 & 0.08 \\
\hline
\end{tabular}

(Kohn et al., 1984a). Muchos autores (Stephan et al., 1980; Beck, 1985a; Audemard, 1993, 1998, 2009; Pindell, 1993; Audemard et al., 2005, entre otros) han indicado que la Placa del Caribe cambia su estilo de deformación evolucionando de un sistema compresivo a uno transpresivo, además de proponer que este cambio ocurrió diacrónicamente entre 19 a $5 \mathrm{Ma}$, de oeste a este en Venezuela. Los pulsos tectónicos encontrados en los modelos termocinemáticos reflejan la importancia de la interacción de la Placa del Caribe con los Andes del Norte como agente de reactivación de importantes sistemas de fallas que llegan hasta el basamento. Pérez et al. (2018) señalan la importancia de la reactivación de estructuras debido a la transpresión generada entre el Caribe y Suramérica, específicamente las figuras 3 y 4 en Pérez et al. (2018) resaltan mecanismos focales representativos de microterremotos reportados por varios autores en el centro-norte de Venezuela (Pérez et al., 1997 a, b; Audemard et al., 2005) y vectores de velocidad del GPS. Los mecanismos focales que se extienden a ambos lados de la falla de Boconó (Figura 1), muestran deslizamiento dextral y fallas inversas. Tanto la falla de San Sebastián como la falla de La Victoria muestran movimiento dextral. Tales fallas pudieron haber controlado la fase más reciente de exhumación (5-0.8 Ma). Esta fase tectónica ha sido definida por Audemard et al. (2005) a partir de la caracterización de los tensores "modernos" de esfuerzos determinados en rocas más jóvenes que el Mioceno, pero también ha sido discriminada en algunos sectores de Los Andes de Venezuela (Audemard y Audemard, 2002; Figura 1), así como también mediante termocronología por trazas de fisión (Kohn et al., 1984b; Bermúdez et al., 2010; 2011; 2014), y en los alrededores del bloque de Maracaibo (Bermúdez et al., 2019), lo cual explicaría la última fase de deformación encontrada en los modelos termocinemáticos propuestos en la presente investigación. Además, que explicaría la presencia de edades cercanas a $5 \mathrm{Ma}$ al sur de la zona de estudio.

El hecho de que las historias termales generadas por FetKin no lleguen hasta la superficie, indica que es necesario incluir la remoción de rocas por erosión en el código para poder exhumar las rocas hasta su posición actual. En los alrededores de la zona de estudio, empleando geomorfología cuantitativa y termocronología detrítica, Flores et al. (2017) reconocen una importante actividad climática regional y un control tectónico local sobre el relieve actual, lo cual resultaría en un incremento significativo en las tasas de exhumación debido a la interacción del clima y la tectónica.

El modelado termocinemático tiene en cuenta los efectos de la exhumación y por ende el flujo de calor en la zona, lo cual relacionamos con un transporte de tipo advectivo del calor que es producido por el efecto de fallas o de procesos de erosión y levantamiento de montañas, modificando la forma de las isotermas (Ehlers, 2005). Todo esto ha sido considerado en el modelo del presente estudio para generar tanto las edades como las historias tiempo-temperatura.

\section{Conclusiones}

La presente investigación permitió corroborar y relacionar los procesos de exhumación con los principales procesos geodinámicos ocurridos en la zona durante el Cenozoico que ya habían 
sido discriminados por distintos autores desde la década de los sesenta por medio de otras aproximaciones. La termocronología permite detectar movimientos verticales producto de la erosión, fallamiento normal o adelgazamiento cortical, o la interacción de tales procesos, así las edades termocronológicas permiten un refinamiento de las fases tectónicas determinadas anteriormente, y establecer su relación con los mecanismos conducentes a la exhumación antes mencionados.

Aunque es posible generar trayectorias tiempo-Temperatura que expliquen los procesos de soterramiento y enfriamiento de las unidades sedimentarias analizadas, se observó durante el desarrollo de la investigación la importancia de incluir en el modelo fallas verticales que corten gran parte de las unidades, tales fallas pudiendo generarse durante los procesos de extensión multidireccional y reactivación de las mismas durante las fases compresivas. Adicionalmente, para lograr una mejor reproductibilidad de las edades y de las historias termales para la zona de estudio, es importante tomar en cuenta procesos como la erosión, geometría de fallas y distintos valores de acortamiento.

Herramientas novedosas como el código FetKin amarrado a un contexto geodinámico, proporcionan trayectorias de tiempo-Temperatura y parámetros termales como la temperatura basal y la tasa de producción de calor radiogénico, que pueden ser utilizados para hacer predicciones de primer orden como, por ejemplo, cuándo entraron
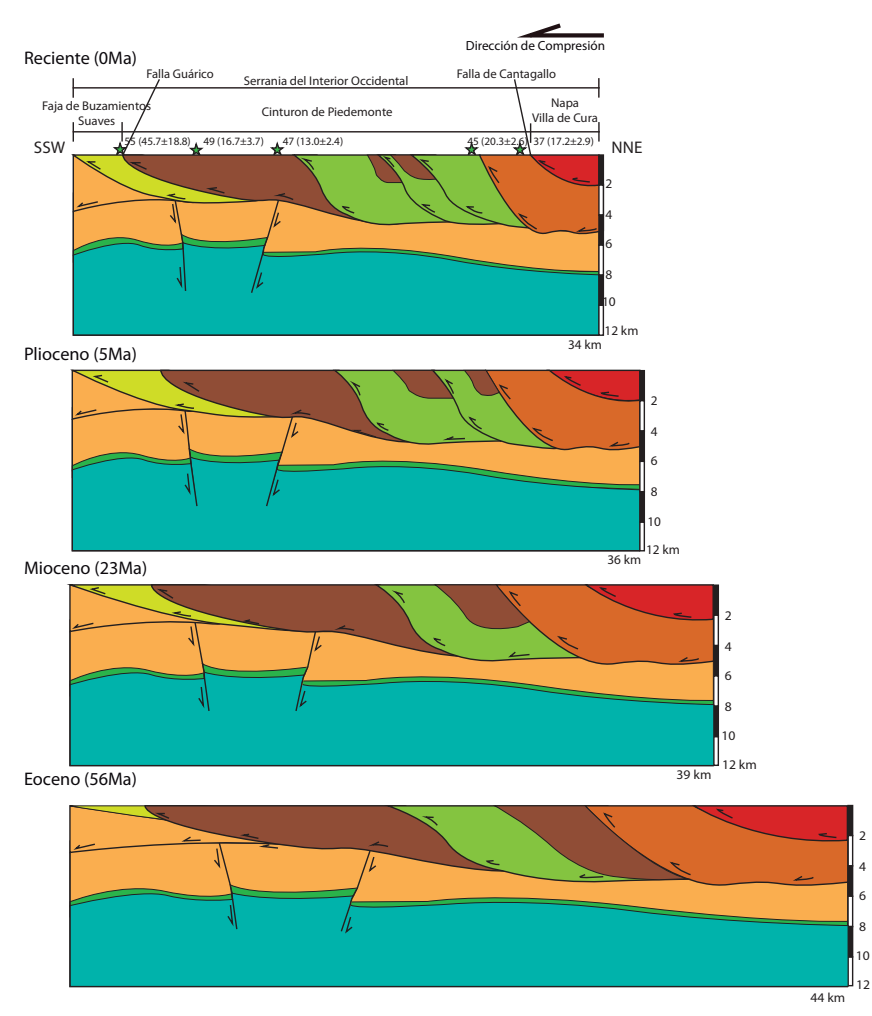
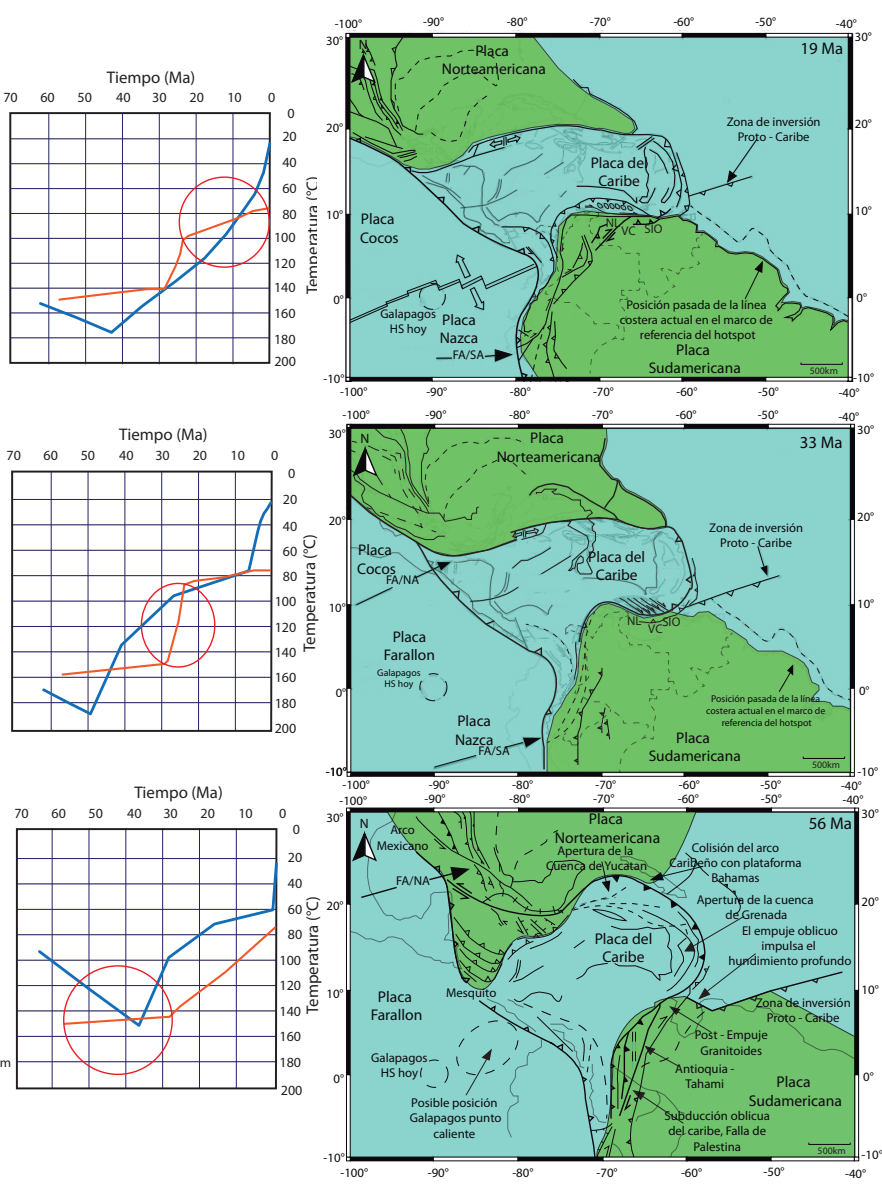

Figura 9 Reconstrucción de la historia de deformación de la zona de estudio. A la izquierda se observan las secciones balanceadas realizadas en 2D MOVE ${ }^{\circledR}$, en el centro las historias termales predichas por FetKin y HeFTy, en la cual el círculo rojo enmarca el pulso tectónico correspondiente y a la derecha la reconstrucción paleogeográfica mostrando los efectos de la colisión oblicua entre las placas del Caribe y Sudamericana (Figura de la derecha modificada de Pindell y Kennan, 2009). 
diferentes rocas generadoras en la ventana de petróleo. Al realizar la reconstrucción de la historia de deformación de la zona se discriminan 4 pulsos tectónicos de enfriamiento diferentes: 1) 48 a 40 Ma, 2) 40 a 23 Ma, 3) 23 a 5 y 4) finalmente, un pulso entre 5 a $0 \mathrm{Ma}$. El primero está relacionado con la convergencia entre las placas del Caribe y Sudamericana la cual se inicia en Colombia a finales del Mesozoico, causando el emplazamiento de las Napas de Lara, el segundo está relacionada con el enfriamiento causado por la subducción de la placa del Caribe por debajo del cinturón deformado del Caribe, el tercero se explicaría por la continuación de la subducción de la placa del Caribe bajo la placa Suramericana, y finalmente, el último pulso podría estar relacionado con la reactivación de diferentes fallas en un contexto transpresivo, y la exhumación de los Andes de Mérida.

Nuestros resultados apoyan una deformación más intensa en el norte lo que sugiere un gradiente de deformación norte-sur. Específicamente en el intervalo de 56 a $23 \mathrm{Ma}$, al final del Mioceno temprano se produce el emplazamiento de estructuras como las Napas de Villa de Cura y en el intervalo de 23 a 0 Ma, la relación entre ambas placas cambia su estilo de deformación evolucionando de un sistema compresivo a uno transpresivo lo cual ya había sido mencionado antes por diferentes autores aquí citados.

Se observa que el flujo de calor en esta zona es afectado por los procesos de erosión formadores del relieve, y no está estrechamente ligado a un fallamiento activo y por ende a una actividad sísmica mayor. En contraste se identifica que, hacia el sector de la Serranía del Litoral, sí se genera un mayor fallamiento y actividad sísmica, con sismos que tienen una magnitud que van desde Mw 2 a 3.5 , y esto se relaciona con un alto flujo de calor.

\section{Agradecimientos}

Esta investigación es parte del trabajo de grado de la primera autora para optar al título de Ingeniera
Geóloga en la Universidad Pedagógica y Tecnológica de Colombia (UPTC), Sogamoso, Colombia, por tal razón agradecemos a esta institución por el apoyo brindado durante el desarrollo de la presente investigación. Adicionalmente, agradecemos el financiamiento proporcionado a través del proyecto DIN-SGI-3104 de la Universidad Pedagógica y Tecnológica de Colombia (UPTC). Agradecemos a los Doctores Richard Ketcham, Andrés Mora y Mauricio Parra por facilitar el software Fetkin, y Fetkin prep. Finalmente agradecemos a la empresa Petroleum Experts LTD (PETEX) por haber facilitado la licencia académica de $\mathrm{MOVE}^{\circledR}$ a la UPTC. Agradecemos a Alejandro Escalona, Jesús García-Zaldivar, y a los editores Laura Perucca y Franck Audemard por sus invaluables comentarios y sugerencias que ayudaron a mejorar la calidad de la presente investigación.

\section{Referencias}

Aguasuelos Ingeniería, 1990, Modernización de datos geológicos en el Frente de Montañas. Estratigrafia-Sedimentació, Caracas: Aguasuelos Ingeniería para Corpoven S.A. Volumen III, Informe inédito.

Almendral, A., Ketcham, R., Styron R., 2015a, User's manual. FETKIN: Finite Element Thermo-Kinematics Version 2.0, Instituto Colombiano del Petróleo, 38p.

Almendral, A., Wilmer, R.,Parra, M., Mora, A., Ketcham, R.,Raghib, M., 2015b, FETKIN: Coupling kinematic restorations and temperature to predict thrusting, exhumation histories, and thermochronometric ages: AAPG Bulletin, 99(8),1557-1573. https:// doi.org/10.1306/07071411112

Audemard, F. A., 1984, Evaluación geológica de la cuenca del Tuy para fines de investigaciones neotectónicas. Trabajo Especial de Grado, Universidad Central de Venezuela, Inédito.

Audemard, F. A., 1993, Néotectonique, Sismotectonique et Aléa Sismique du Nordouest du Vénézuéla (Systéme de failles de 
Oca-Ancón), Tesis de Doctorado, Université Montpellier II, 369 p.

Audemard, F. A., 1997, Holocene and historical earthquakes on the Boconó fault system, southern Venezuelan Andes: Trench Confirmation: Journal of Geodynamics, 24, 155-167. https://doi.org/10.1016/ S0264-3707(96)00037-3

Audemard, F. A., 1998, Evolution géodynamique de la façade nord sud-americaine: Nouveaux apports de l'histoire géologique du bassin de Falcón, Vénézuéla. dans 3rd Geological Conference of the Geological Society of Trinidad and Tobago and 14th Caribbean Geological Conference, Port of Spain, Trinidad, 1995, 2, 327-340.

Audemard, F. A., 2009, Key issues on the postMesozoic Southern Caribbean Plate boundary. En James, K. H., Lorente, M. A., Pindell, J. L. (eds), The Origin and Evolution of the Caribbean Plate, Geological Society, London, Special Publications. 328(1), 569586. https://doi.org/10.1144/SP328.23

Audemard, F. A., 2014, Active block tectonics in and around the Caribbean: A Review. En Schmitz, M., Audemard, F. A., Urbani, F. (eds): El Límite Noreste de la Placa Suramericana - Estructuras Litosféricas de la Superficie al Manto (The Northeastern Limit of the South American Plate Lithospheric Structures from Surface to the Mantle) Editorial Innovación Tecnológica, Facultad de Ingeniería-Universidad Central de Venezuela/FUNVISIS.

Audemard, F.A., Castilla, R., 2016, Present-day stress tensors along the southern Caribbean plate boundary zone from inversion of focal mechanism solutions: a successful trial: Journal of South American Earth Sciences 71, 309-319. https://doi.org/10.1016/j. jsames.2016.06.005

Audemard, F. A., De Santis, F., Singer, A., Ramos, C., 1995, El Sistema de Fallas de La Victoria, Venezuela Norcentral: Trazas Activas, Complejidades Estructurales,
Cinemática y Sismicidad Asociada. En IX Congreso Latinoamericano de Geología. (Diskette).

Audemard, F. A., Machette, M., Cox, J., Hart, R., Haller, K., 2000, Map of Quaternary Faults of Venezuela. Scale 1:2,000,000. Acompañado por noticia explicativa: Map and Database of Quaternary Faults in Venezuela and Offshore regions (USGS Open-File Report 00-18, 78 p). A project of the International Lithosphere Program Task Group II-2: Major active Faults of the World (Regional Coord.: Carlos Costa, Univ. San Luis-Argentina, ILP II-2 co-chairman Western Hemisphere: Michael Machette, USGS-Colorado).

Audemard, F.A., Singer, A., Soulas, J.P., 2006, Fallas y campo de esfuerzos cuaternarios de Venezuela: Revista de la Asociación Geológica Argentina, 61, 4, 480-491.

Audemard,F.E., Audemard, F.A.,2002, Structure of the Mérida Andes, Venezuela: relations with the south America-caribbean geodynamic interaction: Tectonophysics 345, 299-327. https://doi.org/10.1016/ S0040-1951(01)00218-9

Audemard, F.E., Romero, G., Rendón H., Cano, V., 2005, Quaternary fault kinematics and stress tensor along the southern Caribbean from fault-slip data and focal mechanism solutions, Earth-Science Review, 69, 181-233. https:// doi.org/10.1016/j.earscirev.2004.08.001

Ave-lallemant H.G. y Sisson V.B., 2005, Exhumation of eclogites and blueshists in northern Venezuela: Constrains from kinematic analysis of deformation structures. En H. G. Avé-Lallemant y V. B. Sisson, (eds.), Caribbean-South American plate interactions, Venezuela: Geological Society of America Special Paper 394, 193-206. https:// doi.org/10.1130/0-8137-2394-9.193

Bassin, C., Laske, G., Masters, G., 2000, The Current Limits of Resolution for Surface Wave Tomography in North America: EOS Trans AGU, 81, F897. 
Beck, C., 1977, Geología de la Faja Piemontina y del frente de Montaña en el Noreste del Estado Guárico, Venezuela. Mem. Vo Congreso Geología Venezuela, Caracas II, 759-788; Mapa Geológico de Venezuela a escala 1:50000, hojas de Altagracia de Orituco y de Taguay.

Beck, C., 1978, Polyphasic Tertiary tectonics of the Interior Range in the central part of the Western Caribbean Chain, Guárico State, northern Venezuela. Trans. En VIII th Caribb. Geol. Conf. Curaçao, Macgillavry, H.J., Beets, D.J. (Eds.), Geologic Mijnb, 57, 2, 99-104.

Beck, C., 1985a, La Chaine Caraibe au méridien de Caracas: Géologie, téctogenèse, place dans l'évolution géodynamique mésozoïque - cénozoïque des caraïbes méridionales. Thèse d'état, Paris.

Beck, G., 1985b, Caribbean colliding, Andean drifting and the Mesozoic-Cenozoic geodynamic evolution of the Caribbean. En VI Congreso Geológico Venezolano, Caracas, 10, 6575-6614.

Beck, C., 1985c, Las Napas de Aragua -Cadena Caribe Central- y la historia Mesozoica del margen sur del Caribe a lo largo del Meridiano de Caracas. En Symposium Géodynamique des Caraibes Paris, A. Mascle Edr., Es Technip, 541-551.

Bell, J. S., 1968, Geología de la región de Camatagua, estado Aragua: Boletín de Geología, Caracas, 9(18), 291-440.

Bellizzia, A., 1972, Sistema montañoso del Caribe, borde sur de la placa Caribe ¿es una cordillera alóctona? En VI Conf. Geol. Caribe, Margarita, Venezuela, 24-258.

Bellizzia, A., Pimentel, N., Bajo, R., 1976, Mapa geológico-estructural de Venezuela. Scale 1: 500,000. Ministerio de Energía y Minas, Ed. Foninves, Caracas.

Bellon, H., Vila, J. M., Mercier de Lepinay, B., 1985, Chronologie ${ }^{40} \mathrm{~K}-{ }^{39} \mathrm{Ar}$ et affinités des manifestations magmatiques au Crétacé et au Paléogéne dans l'ile d'Hispaniola. En Mascle, A., Biju-Duval, B. (eds).
Géodynamique des Caribes, Éditions Technip, Paris, 329-340.

Bermúdez, M., Flores-Ferrín, M., 2019, Aplicaciones de la termocronología por trazas de fisión en Venezuela: Estado actual, perspectivas y visión integradora: Boletín de Geología, 41(3), 175-200. https://doi. org/10.18273/revbol.v41n3-2019009

Bermúdez, M., Kohn, B., Van der Beek, P., Bernet, M., O’Sullivan, P., Shagam, R., 2010, Spatial and temporal patterns of exhumation across the Venezuelan Andes: Implications for Cenozoic Caribbean geodynamics: Tectonics, 29(5), TC5009. https://doi. org/10.1029/2009TC002635

Bermúdez, M., Van der Beek, P.,Bernet, M., 2011, Asynchronous Miocene-Pliocene exhumation of the central Venezuelan Andes: Geology, 39(2), 139-142. https://doi. org/10.1130/G31582.1

Bermúdez, M., Van der Beek, P., Bernet, M., 2013, Strong tectonic and weak climatic control on exhumation rates in the Venezuelan Andes: Lithosphere, 5(1), 3-16. https://doi. org/10.1130/L212.1

Bermúdez, M.A., Kohn, B., Van der Beek, P., Bernet, M., 2014, Patrones de exhumación de los Andes venezolanos: Un aporte de la termocronología y de la modulación numérica termocinemática 3D: Acta Científica Venezolana, 65(2), 17-27.

Bermúdez, M.A., Bernet, M., Kohn, B.,Brichau, S., 2019, Exhumation-Denudation History of the Maracaibo Block, Northwestern South America: Insights from Thermochronology. En Cediel F., Shaw R.P. (eds), Geology and Tectonics of Northwestern South America. Frontiers in Earth Sciences. Springer, Cham, 879-898. https://doi. org/10.1007/978-3-319-76132-9_13

Blin, B., 1989, Contribution à l'étude géologique de la frontière sud de la plaque Caraïbe: le front de la chaîne Caraïbe vénézuélienne entre la Serranía de Portuguesa et la région de Tiznados (surface et subsurface). Apport des données paléomagnétiques. 
Interprétation géodynamique. Universite de Bretagne Occidentale. Tesis doctoral. 375 p. Reproducido en Geos, UCV, Caracas, (42), 134-135.

Boschman, L, Van Hinsbergen, D., Torsvik, T., Spakman, W., Pindell, J., 2014, Kinematic reconstruction of the Caribbean region since the Early Jurassic: Earth-Science Reviews, 138, 102-136. https://doi.org/10.1016/j. earscirev.2014.08.007

Brady, R., Ducea, M., Kidder, S., Saleeby, J., 2005, The distribution of radiogenic heat production as a function of depth in the Sierra Nevada Batholith, California: Lithos, 86(3), 229 -244. https://doi.org/10.1016/j. lithos.2005.06.003

Bucher, W. H., 1950, Mapa geológico - tectónico de los Estados Unidos de Venezuela (con excepción del Territorio Amazonas y parte del estado Bolívar). Auspiciado por el Min. Fomento, Servicio Técnico de Minería y Geología. Publicado por The Geological Society of America. Escala 1: 1,000,000.

Carrillo, E., Mora, A., Ketcham, R., Amorocho, R., Parra, M., Costantino, D., Robles, W., Avellaneda, W., Carvajal, J.S., Corcione, M.F., Bello, W., Figueroa, J.D., Gómez, J.F., González, J.L., Quandt, D., Reyes, M., Rangel, A.M., Román, I., Pelayo, Y., Porras, J., 2016, Movement vectors and deformation mechanisms in kinematic restorations: A case study from the Colombian Eastern Cordillera: Interpretation, 4 (1), T31-T48. https://doi.org/10.1190/INT-2015-0049.1

Cediel, F., R. Shaw, P., Cáceres, G., 2003, Tectonic assembly of the Northern Andean Block. En C. Bartolini, R. T. Buffler, J. Blickwede, (eds.), The Circum-Gulf of Mexico and the Caribbean: Hydrocarbon habitats, basin formation, and plate tectonics: AAPG Memoir 79, 815- 848. https://doi. org/10.1306/M79877C37

Codazzi, A., 1841a, Resumen de la geografía de Venezuela. H. Fournier y Co., París. 648 p. Codazzi, A., 1841b, Atlas físico y político de la
República de Venezuela. H. Fournier y Co., París.

Cruz, L., Fayon, A., Teyssier, C., Weber, J., 2007, Exhumation and deformation processes in transpressional orogens: The Venezuelan Paria Peninsula, SE CaribbeanSouth American plate boundary: Special Paper of the Geological Society of America, 434, 149-165. https://doi. org/10.1130/2007.2434(08)

Daal, J., Lander, R., 1993, Yucal-Placer Field, Venezuela, Eastern Venezuela basin, Guárico basin. En Foster, N.H.,Beaumont, E.A., (eds.), American Association of Petroleum Geologists Treatise: Structural Traps VIII, 307-328.

Davies,J., 2013, Global map of solid Earth surface heat flow: Geochemistry, Geophysics, Geosystems, 14(10), 4608-4622. https:// doi.org/10.1002/ggge.20271

Dengo, G., 1947, Informe geológico sobre el proyecto de autopista Caracas La Guaira: Revista de Fomento, Caracas, 9-10(69), 133-154.

Dengo, G., 1950a, Eclogitic and glaucophane amphibolites in Venezuela: Eos, Transactions American Geophysical Union, 31(6), 873-878. https://doi.org/10.1029/ TR031i006p00873

Dengo, G., 1950b, Geología de la región de Caracas: Revista de Fomento, Caracas, 12 (73), 213-298.

Dengo, G., 1951, Geología de la región de Caracas: Boletín de Geología, Caracas, 1(1), 39-115.

Dengo, G., 1953, Geology of the Caracas region, Venezuela: Bulletin Geological Society of America, 64 (1), 7-40.

Ehlers, T., 2005, Crustal thermal processes and the interpretation of thermochronometer data: Reviews in Mineralogy and Geochemistry, 58(1),315-350.

Escalona, A., Mann, P., 2011, Tectonics, basin subsidence mechanisms, and paleogeography of the Caribbean-South 
American plate boundary zone: Marine and Petroleum Geology, 28, 8-39. https:// doi.org/10.1016/j.marpetgeo.2010.01.016

Flores, M., Bermúdez, M., Bustos, X., Bernet, M., Vivian, C., Arcia, S., Schmitz, M., 2017, Análisis de los procesos controladores en la evolución topográfica de la subcuenca del rio Guárico, Venezuela: mediante métodos multiherramientas: Terra Nueva Etapa, 33(54), 71-106.

French, G.D., Schenk, C.J., 2004, Faults of the Caribbean Region (flt6bg), U.S. Geological Survey, Central Energy Resources Team.

Freymueller, J. T., Kellogg, J. N., Vega, V., 1993, Plate motions in the north Andean region: Journal of Geophysical Research, 98, 21853-21863.

Girad, D., 1981, Pétrologie de quelques séries spilotiques mésozoïques du domaine Caraibe et des ensembles magmatiques de l'ile de Tobago. Thèse Doct,Universidad De Bretagne Occidentale, Brest, 229 p.

Giunta, G., Orioli S., 2011, The Caribbean plate evolution: trying to resolve a very complicated tectonic puzzle. En Sharkov, E. (ed.), New frontiers in tectonic researchgeneral problems, sedimentary basins and island arcs, InTech. 2011. https://doi. org/10.5772/18723

González Silva, L. A., Picard, X., 1972, Sedimentación y Aloctonia en el frente de montañas de Guárico. En Mem. VI Cong. Geol. Caribe, Margarita, Venezuela, 83-88.

Hackley, P., Urbani, F., Karlsen, A., Garrity, C., 2005, Geologic Shaded Relief Map of Venezuela. U.S. Geological Survey Report 2005-1038.

Hernández, M., 2006, Modelado numérico termal 1D de la cuenca oriental de Venezuela. Universidad Simón Bolívar, Venezuela, Caracas, Tesis pregrado.

Hess, H.H., 1938, Gravity anomalies and island arc structurs with particular reference to the west indies: Proceedings of the American Philosophical Society, 79(1), 71-96.
Horváth, Á., Bohus, L.O., Urbani, F., Marx, G., Piróth, A., Greaves, E.D., 2000, Radon concentrationsin hot spring watersinnorthern Venezuela: Journal of Environmental Radioactivity, 47(2),127-133. https://doi. org/10.1016/S0265-931X(99)00032-6

Jarvis, H. A., 1966, Geología de la región río Paorío Tiznados, estados Cojedes y Guárico, Venezuela: Boletín de Geología, Caracas, 8, 73-115.

Karsten, H., 1850, Beitrage zur Kenntniss der Gesteine der nördlichen Venezuela. Zeitschr. Der Deutsch: Geologischen Gesellschaft, Berlin, 11, 345-361.

Karsten, H., 1858, Über die geognostischen Verhältnisse des westlichen Columbien, der heutigen Republiken Neu-Granada und Equador: 32nd versammlung Deutscher Naturfoscher und Ărzte zu wien im September 1856, Amtlicher Beritcht Viena, 80-117, 7 pl., 1 mapa geol. 1: 8,000,000.

Karsten, H., 1862, Die geognostische Beschaffenheit der gebirge Der Provinz von Caracas. Zeitschr der Deutsch: Geologischen Gesellschaft, 14, 282-287.

Karsten, H., 1886, Géologie de l’ancienne Colombie bolivarienne, Vénézuela, Nouvelle-Grenade et Ecuador. Berlín: R. Friedlander y Sohn, 62 p.

Ketcham, R., 1996, Distribution of heat-producing elements in the upper and middle crust of southern and western Arizona: evidence from the core complexes: Journal of Geophysical Research, 101(B6), 13611 -13632. https:// doi.org/10.1029/96JB00664

Ketcham, R., 2017, Manual HeFTy versión 1.9.3. Department of Geological Science. The University of Texas at Austin, 85p.

Kohn, B.P., Shagam, R., Subieta, T., 1984a, Results and preliminary implications of sixteen fission-track ages from rocks of the western Caribbean Mountains, Venezuela. En William E. Bonini, Robert B. Hargraves, Reginald Shagam (eds.), The CaribbeanSouth American Plate Boundary and 
Regional Tectonics, Geological Society of America, 162, 415-421. https://doi. org/10.1130/MEM162-p415

Kohn, B.P, Shagam, R., Banks, P., Burkley, L., 1984b, Mesozoic-Pleistocene fission track ages on rocks of the Venezuelan Andes and their tectonic implications. En William E. Bonini, Robert B. Hargraves, Reginald Shagam (eds.), The Caribbean-South American Plate Boundary and Regional Tectonics, Geological Society of America, 162, 365-384. https://doi.org/10.1130/ MEM162-p365

Konigsmark, T. A., 1958, Geology of the northern Guárico-Lake Valencia area: Boletín Informativo Asociación Venezolana de Geología, Minería y Petróleo, 1(5), 151-165.

Konigsmark, T. A., 1965, Geología del área de Guárico septentrional - Lago de Valencia, Venezuela: Boletín de Geología, Caracas, 6 (11), 209-285.

Kumar, P., Reddy, G., 2004, Radioelements and heat production of an exposed Archean crustal cross-section, Dharwar craton, south India: Earth and Planetary Science Letters 224, 309-324. https://doi.org/10.1016/j. epsl.2004.05.032

Lachenbruch, A.H., 1968, Preliminary geothermal model of the Sierra Nevada: Journal of Geophysical Research 73, 6977-6989.

Lar, A., 1992, Étude géochimique de massifs basiques et ultrabasiques (Apa, Todasana, Tinaquillo) de la chaîne tertiaire Caraïbe $\mathrm{du}$ Venezuela. Genèse de magmas mantelliques et interaction manteau-croûte. Universite Paul Sabatier, Toulouse, France. Tesis de doctorado, $229 \mathrm{p}$.

Laske, G., Masters., G., Ma, Z., Pasyanos, M., 2013, Update on CRUST1.0 - A 1-degree Global Model of Earth's Crust: Geophysical Research Abstracts, 15, EGU2013-2658.

Liddle, R. A., 1928, The Geology of Venezuela and Trinidad. MacGovan, Fort Worth, Texas, $552 \mathrm{p}$.
Liddle, R. A., 1946, The Geology of Venezuela and Trinidad, $2^{\text {nd }}$ ed., Paleontological Research Institution, Ythaca, N.Y., 890 p.

Liuzzi, D., Schmitz, M., Jacome, M., Sánchez, J., 2006, Adelgazamiento de sedimentos Cretácicos-Oligocenos bajo la Serranía del Interior, Noreste de Venezuela: Evidencia a partir de observaciones de sísmica profunda. En IX Simposio Bolivariano Exploración Petrolera en las Guencas Subandinas.

Locke, B., Garver, J., 2005, Thermal evolution of the eastern Serranía del Interior foreland fold and thrust belt, northeastern Venezuela, based on apatite fission-track analyses. En Avé Lallemant, H.G., Sisson, V.B., (Eds.), Caribbean-South American plate interactions, Venezuela: Geological Society of America Special Paper 394, 315-328, https://doi. org/10.1130/2005.2394(12).

Loubet, M., Polve, M., Richard, P., Allegre C.J., 1980, Geochemical studies in orogenic herzolites: evidences about multiple magmatic events. En Associations mafiques et ultramafiques dans les orogénes, Grenoble, Colloques, 269-277.

Loubet, M. Montigny, R., Chachati, B., Duarte, N., Lambret, B. Martin, C., Thuizart R., 1985, Geochemical and geochronological constraints on the geodynamic development of the Caribbean Chain of Venezuela. En Symposium Géodynamique des Caraibes Paris, A. Mascle Edr., Eds Technip, 553-566.

Lugo, J., Mann, P., 1992, Colisión oblicua y formación de una cuenca foreland durante el Paleoceno tardío al Eoceno medio; Cuenca de Maracaibo, Venezuela. En III Congreso Geológico de España y VIII Congreso Latinoamericano de Geología, Salamanca, 4, 60-64.

Lugo, J., Mann, P., 1995, Jurassic-Eocene tectonic evolution of Maracaibo Basin, Venezuela. Petroleum Basins of South America: American Association of Petroleum Geologists Memoir 62, 699-725.

Maclachlan, J. C., 1952, Geology of the La Victoria area, Venezuela. Princeton University, Tesis doctorado, $133 \mathrm{p}$. 
Mann, P., Escalona, A., Castillo, M., 2006, Regional geologic and tectonic setting of the Maracaibo supergiant basin, western Venezuela: American Association of Petroleum Geologists Bulletin 90(4), 445478. https://doi.org/10.1306/10110505031

Maresch, W., 1974, Plate tectonic origin of the Caribbean Mountain System of northern South America: Discussion and proposal: Geological Society of America Bulletin, 85(5), 669-682. https://doi.org/10.1130/0016$7606(1974) 85<669: \mathrm{PTOOTC}>2.0$. $\mathrm{CO} ; 2$

Menéndez, A., 1966, Tectónica de la parte central de las montañas occidentales del Caribe, Venezuela: Boletín de Geología, Caracas, 8 (15), 116-139.

Ministerio de Minas e Hidrocarburos, 1970, Léxico Estratigráfico de Venezuela: Boletín de Geología, Publicaciones Especiales, 4, 464 p.

Mora, A., Casallas, W., Ketcham, R., Gomez, D., Parra, M., Namson, J., Ghorbal, B., 2015, Kinematic restoration of contractional basement structures using thermokinematic models: A key tool for petroleum system modeling: AAPG Bulletin, 99(8), 1575-1598. https://doi.org/10.1306/04281411108

Mussett, E., Khan, A., 2000, Looking Into the Earth: An Introduction to Geological Geophysics. Cambridge University, 269-283.

Ollarves, R., Audemard, F., Espínola, E., Hernández, J., Rojas, E., Alezones, R., Falcón, R., 2004, Neotectónica de la Cuenca de Barlovento. En Memoria I Congreso Latinoamericano de Sismología, Armenia.

Oxburg E. R., 1965, Geología de la región oriental del estado Carabobo, Venezuela: Boletín de Geología, Caracas, 6(11), 113-208.

Palma, M., Audemard, F., Romero, G., 2010, Nuevos mecanismos focales para Venezuela y áreas vecinas 2005-2008: importancia de la densificación y distribución de la Red Sismológica Nacional: Revista Técnica de la Facultad de Ingeniería Universidad del Zulia, 33(2), 108-121.
Peirson, A. L., 1963, Galera member of the Quebradón Formación: Boletín Informativo de la Asociación Venezolana de Geología, Mineria y Petróleo, 6(5), 141-150.

Peirson, A. L., 1965, Geology of the Guárico Mountain Front: Boletín Informativo de la Asociación Venezolana de Geología, Mineria y Petroleo, 8(7), 183-212.

Peirson, A. L., Salvador, A., Stainforth R. M., 1966, The Guárico formation od NorthCentral Venezuela: Boletín Informativo de la Asociación Venezolana de Geología, Mineria y Petroleo, 9(7), 183-224.

Pennington, W., 1981, Subduction of the Eastern Panama Basin and Seismotectonics of Northwestern South America: Journal of Geophysical Research, 86(B11), 10753-10770. https://doi.org/10.1029/ JB086iB11p10753

Pérez de Armas, J., 2005, Tectonic and thermal history of the western Serranía del Interior foreland fold and thrust belt and Guárico basin, north-central Venezuela: Implications of new apatite fission-track analysis and seismic interpretation. En Avé Lallemant, H.G., Sisson, V.B., (Eds.), CaribbeanSouth American plate interactions, Venezuela: Geological Society of America Special Paper, 394, 271-314. https://doi. org/10.1130/0-8137-2394-9.271

Pérez, O., Aggarwal, Y., 1981, Present-day tectonics of southeastern Caribbean and northeastern Venezuela: Journal of Geophysical Research, 86(B11), 10791-10805. https://doi. org/10.1029/JB086iB1 1p10791

Pérez, O., Bilham, R., Bendick, R.,Hernández, N., Hoyer, M., Velandia, J. R.,Moncayo, C., Kozuch, M., 2001a, Velocidad relativa entre las placas del Caribe y Sudamérica a partir de observaciones dentro del sistema de posicionamiento global (GPS) en el norte de Venezuela: Interciencia, 26, 69-74.

Pérez, O., Bilham, R., Bendick, R.,Velandia, J. R., Hernández, N.,Moncayo, C., Hoyer, M., Kozuch, M., 2001b, Velocity field across the southern Caribbean Plate 
boundary and estimates of CaribbeanSouth American Plate motion using GPS geodesy 1994-2000: Geophysical Research Letters, 28(15), 2987-2990. https://doi. org/10.1029/2001GL013183

Pérez, O., Sanz C., Lagos G., 1997a, Microseismicity, tectonics and seismic potential in southern Caribbean and northern Venezuela: Journal Seismology, 1, 15-28. https://doi.org/10.1023/A:1009710122083

Pérez, O., Jaimes M., Garciacaro E., 1997b, Microseismicity evidence for subduction of the Caribbean plate beneath the South American plate in northwestern Venezuela: Journal of Geophysical Research Solid Earth, 102(B8), 17875-17881. https://doi. org/10.1029/96JB03174

Pérez, O., Wesnousky, S., De La Rosa, R., Márquez, J., Uzcátegui, R., Quintero, C., Liberal, L., Mora-Páez, H., Szeliga, W., 2018, On the interaction of the North Andes plate with the Caribbean and South American plates in northwestern South America from GPS geodesy and seismic data: Geophysical Journal International, 214(3),1986-2001, https://doi.org/10.1093/gji/ggy230

Petroleum Experts, 2019, MOVE the Structural Geology Toolkit. Edinburgh, 32p.

Piburn, M. D., 1968, Metamorfismo y estructura del grupo Villa de Cura, Venezuela septentrional: Boletín Geologíca, 9(18), 183-289.

Pindell, J., 1993, Mesozoic - Cenozoic tectonic and stratigraphy development of the Eastern Caribbean and Northern South American, Implications for Eastern Venezuela: Informe interno de PDVSA, EPG 10462.

Pindell, J., Kennan, L., 2001a, Kinematic Evolution of the Gulf of Mexico and Caribbean. En R.H. Fillon, N.C. Rosen, P. Weimer, A. Lowrie, H. Pettingill, R.L. Phair, H.H. Roberts, H.H. van Hoom (Eds.), Petroleum Systems of Deep-Water BasinsGlobal and Gulf of Mexico Experience, 21. https://doi.org/10.5724/gcs.01.21.0193
Pindell, J., Kennan, L., 2001b, Processes and Events in the Terrane Assembly of Trinidad and Eastern Venezuela. En R.H. Fillon, N.C. Rosen, P. Weimer, A. Lowrie, H. Pettingill, R.L. Phair, H.H. Roberts, H.H. van Hoom (Eds.), Petroleum systems of Deep-Water BasinsGlobal and Gulf of Mexico Experience, 21. https://doi.org/10.5724/gcs.01.21.0159

Pindell, J., Kennan, L., 2009, Tectonic evolution of the Gulf of Mexico, Caribbean and northern South America in the mantle reference frame: an update: Geological Society, London, Special Publications 328, 1-55. https://doi. org/10.1144/SP328.1

Pindell, J., Higgs, R., Dewey, J., 1998, Cenozoic palinspatic reconstruction, paleogeographic evolution and hydrocarbon setting of the northern margin of South America. En Pindell, J., Drake, C. (Eds.), Paleogeographic Evolution and Non-glacial Eustasy, Northern South America: Society for Sedimentary Geology, Special Publications, 58, 45-85. https://doi.org/10.2110/pec.98.58.0045

Pindell J., Kennan, L., Maresch, W. V., Staneck, K. P., 2005, Plate-kinematics and crustal dynamics of circum-Caribbean arc-continent interactions: Tectonic controls on basin development in Proto-Caribbean margins. En Avé-Lallemant, H. G., Sisson, V. B. (Eds.), Caribbean-South American plate interactions, Venezuela: Geological Society of America Special Paper 394, 7-52. https://doi. org/10.1130/0-8137-2394-9.7

Russo, R., Speed, R. C., 1992, Oblique collision and tectonic wedging of the South American continent and Caribbean terranes: Geology, 20(5), 447-450. https://doi.org/10.1130/0091$7613(1992) 020<0447$ :OGATWO > 2.3. $\mathrm{CO} ; 2$

Sagna, I., 1990, Datation potassium-argon et argon 40 - argon 39 de roches métamorphiques de la Chaîne Caraïbe du Vénézuela. Université Louis Pasteur, Strasbourg. Tesis de doctorado, $254 \mathrm{p}$. 
Sagna, I., Montigny, R., Urbani F., Loubet. M., 1988, K-Ar ages of igneous rocks from the Caribbean chain of Venezuela: Chemical Geology, 70(1-2), 15.

Santamaria, F., Schubert, C., 1975, Geoquímico y Geocronología del contacto entre las placas del Caribe y América del Sur (Venezuela Septentrional): Boletin informativo, Asociación Venezolana de Geología, Minería y Petróleo, 18(1), 1-38.

Schubert, C., 1983, Aspectos neotectónicos de la zona de falla de La Victoria: FUNVISIS. Reporte inédito.

Schottky, A., 1877, Die Kupfererze des Districtes von aroa, Venezuela. Inaugural Dissertation von Tübingen, Breslau, 36 p. En Jahresbericht der schlesischen Gesellschaft für vaterländische Cultur 55, 45-46. Reimpresión facsimilar en 1997, Boletín de Historia de las Geociencias en Venezuela 61, 31-39.

Seiders, V., 1965, Geología de Miranda central, Venezuela: Boletín de Geología, Caracas, 6(12), 289-416.

Shagam, R., 1960, Geology of central Aragua, Venezuela: GSA Bulletin, 71(3), 249302. https://doi.org/10.1130/0016$7606(1960) 71$ [2 49: G O CAV] 2.0. $\mathrm{CO} ; 2$

Sievers, W. F., 1888, Die cordillere von Mérida, nebst bemerkungen ubre das Karibische Gebirge. Ergebnisse einer mit Unterstützung der Geographischen Gesellshaft zu Hamburg 1884- 1885 ausgeführten Reise, von Dr. W. Sievers. Mit einer geologischen Karte und 15 Profilen in Farbendruck. Geographische Abhandlungen (Herausgegeben von Prof. Dr. Albrecht Penk in Wien), Wien und Olmütz, E. Holzel, Band 3, Heft 1, viii, 238 p. (Mapa: Geognostische Karte der Venezolanischen Cordillere).

Silver, E. A., Casa, J., MacGillavry, H.J., 1975, Geophysical study of the Venezuelan Borderland: GSA Bulletin, 86(2), 213226. https://doi.org/10.1130/00167606 (1975)86<213: G SOTV B $>2.0$. $\mathrm{CO} ; 2$
Singer, A., Audemard, F. A., 1997, Aportes de Funvisis al desarrollo de la geología de fallas activas y de la paleosismología para los estudios de amenaza y riesgo sísmico: Academia de las Ciencias Naturales, Matemáticas y Físicas, Publicación Especial, 33, 25-38.

Sisson, V.B., Avé Lallemant, H.G., Ostos, M., Blythe, A.E., Snee, L.W., Copeland, P., Wright, J.E., Donelick, R.A., Guth, L.R., 2005, Overview of radiometric ages in three allochthonous belts of northern Venezuela: Old zones, new ones, and their impact on regional geology. En Avé Lallemant, H.G., Sisson, V.B., (eds.), CaribbeanSouth American plate interactions, Venezuela: Geological Society of America Special Paper, 394, 91-117. https://doi. org/10.1130/2005.2394(03).

Smith, R. J., 1953, Geology of the Los TequesCúa region, Venezuela: Bulletin of the Geological Society of America 64(1), 41 -64, 1953. https://doi.org/10.1130/00167606(1953)64[41:GOTLTR]2.0.CO;2

Speed, R., 1985, Cenozoic collision of the lesser Antilles arc and continental South America and the origin of the El Pilar Fault: Tectonics, 4(1), 41-69. https://doi.org/10.1029/ TC004i001p00041

Stephan, J. F., 1982, Evolution géodynamique du domaine Caraibe, Andes et chaine Caraibe sur la transversale de Barquisimeto (Vénézuéla). Thésée d'état, Paris.

Stephan, J. F., Beck, C., Bellizia, A., Blanchet, R., 1980, La chaine Caraïbe du Pacifique á l'Atlantique : $26^{\text {th }}$ Géologique International Congress, Résumés C.t., 38-59.

Stephan, J. F., Mercier de Le' Pinay, B., Calais, E., Tardy, M., Beck, G., 1990, Paleogeodynamic maps of the Caribbean: 14 steps from Lias to present: Bulletin de la Société Géologique de France, 8(6), 915-919. https://doi. org/10.2113/gssgfbull.VI.6.915

Sykes, L., McCann y Kafka, A., 1982, Motion of the Caribbean plate during the last 7 million years and implications for earlier Cenozoic 
movements: Journal of Geophysical Research, 87(B13), 10656-10676. https:// doi.org/10.1029/JB087iB13p10656

Taboada, A., Rivera, L., Fuenzalida, A., Cisternas, A., Philip, H., Bijwaard, H., Olaya, J., Rivera, C., 2000, Geodynamics of the Northern Andes: subductions and intra-continental deformation (Colombia): Tectonics 19(5), 787-813. https://doi. org/10.1029/2000TC900004

Urbani, F., 2012, Conversaciones sobre la geología de la Cordillera de la Costa ¿Donde y cuando se formaron las distintas unidades que conforman la Cordillera?: Geos, UCV, Caracas, 42, 148-150.

Urbani, F., 2018, Una revisión de los terrenos geológicos del sistema montañoso del caribe, norte de Venezuela: Boletín de la Academia de Ciencias Físicas, Matemáticas y Naturales de la Universidad Central de Venezuela, Caracas, 129-225.

Urbani, F., Audemard, F.A., Camposano, L., 2005, Cordillera de la Costa, Venezuela: Geological field trip. Southeast Caribbean Continental Dynamics Project: Bolívar y Geodinos, Ministerio de Ciencia y Tecnología.

Van der Hilst, R., Mann P., 1994, Tectonic implications of tomographic images of subducted lithosphere beneath northwestern South America: Geology, 22(5), 451454. https://doi.org/10.1130/00917613(1994)022<0451: TIOTIO>2.3.CO;2
Wagner, G., Van den Haute, P., 1992, Fission track dating. Netherlands: Kluwer, Academic Publishers.

Wall, G. P., 1860a, Report on the geology of Trinidad; or Part I. of the West Indian Survey: Memoirs of the Geological Survey, Londres, $211 \mathrm{p}$.

Wall, G. P., 1860b, On the geology of a part of Venezuela and of Trinidad: Quarterly Journal of the Geological Society London, 16, 460-470. https://doi.org/10.1144/GSL. JGS.1860.016.01-02.62

Weber, J., Dixon, T., 2001, GPS estimate of relative motion between the Caribbean and South American plates, and geologic implications for Trinidad and Venezuela: Geology 29(1), 75-78. https://doi.org/10.1130/0091$7613(2001) 029<0075:$ GEORMB > 2.0. $\mathrm{CO} ; 2$

Weber, J. C., Geirsson, H., Latchman, J. L., Shaw, K., La Femina, P., Wdowinski, S., Norabuena, E., 2015, Tectonic inversion in the CaribbeanSouth American plate boundary: GPS geodesy, seismology, and tectonics of the Mw 6.7, 22 April 1997 Tobago earthquake: Tectonics, 34(6), 1181-1194. https://doi. org/10.1002/2014TC003665

Ysaccis, R., Cabrera, E., Del Castillo, H., 2000, El sistema petrolífero de la Blanquilla, costa afuera Venezuela. En VII Congreso Bolivariano Exploración Petrolera en las Cuencas Subandinas, Caracas, 411-425. 